\title{
Foreign stock holdings: the role of information*
}

\author{
Fernanda Nechio \\ Federal Reserve Bank of San Francisco
}

November, 2010

\begin{abstract}
The household finance literature documents a large fraction of the population not participating in stock markets. It is also puzzling that a much greater share of households do not participate in foreign stock markets. Recent empirical evidence points towards the role of information in determining agents' portfolio choices. I test these results into a model that incorporates information on agents' portfolio allocation decision. Departing from Abel at al (2007), consumers can invest in foreign stocks, in addition to domestic ones. To update their information set, agents have to pay a cost implying that consumers update their portfolio only infrequently. In addition, to account for the initial costs of acquiring information about stock investments, a version of the model also features an entry-cost to be paid at the first period by agents that decide to enter stock market. Agents that invest in foreign stocks are more attentive, updating their portfolio more frequently. After calibrating the model to match returns and volatility for the U.S. economy and different foreign stock investments, I obtain that the minimum entry cost necessary to drive households completely out of stock markets is large (and in line with the equity premium puzzle literature). However, once agents already invest in domestic stock markets, the minimum cost that would drive investors out of foreign stocks market is much smaller. The size of the latter minimum entry cost depends on model parameters assumptions, and small variations on risk aversion and uncertainty about foreign asset returns can make this entry cost small enough to rationally justify the substantial non-participation in foreign stock markets.
\end{abstract}

JEL classification codes: G11, G14, G15

Keywords: participation decision, foreign stocks, information acquisition

${ }^{*}$ For comments and suggestions I thank seminar participants at Dallas Fed, UC Davis, EEA 2010, USC, Princeton University, and San Francisco Fed. I am also grateful to Alan Blinder, Oleg Itskhoki, Nobu Kiyotaki, Pierre-Olivier Gourinchas, Galina Hale, Ricardo Reis, Helene Rey and Chris Sims for comments and suggestions. The views expressed in this paper are those of the author and do not necessarily reflect the position of the Federal Reserve Bank of San Francisco or the Federal Reserve System. E-mail: fernanda.nechio@sf.frb.org. 


\section{Introduction}

One of the main puzzles in the finance literature is the so-called participation puzzle; a large fraction of the population does not participate in the stocks market, despite the large equity premium. ${ }^{1}$ It is also puzzling that a much greater share of households do not participate in foreign stock markets, notwithstanding the well-known gains of keeping a diversified portfolio of assets. While substantial normative and positive analysis has been done in trying to explain the former puzzle, the knowledge about household ownership of foreign stocks is more constrained.

This paper contributes to the participation puzzle literature in focusing on international holdings of stocks. On the one hand, the household finance literature describes the decision to invest in stocks as a two-step process, in which households firstly decide on whether to enter the stock market, and subsequently decide on the share of assets to hold in their portfolio. On the other hand, the international finance literature has focused on the share of foreign assets agents hold in their portfolio, documenting a large home bias on agents' portfolio holdings. However, preceding the decision about the share held of foreign assets, agents decide on whether to own foreign assets, in particular, in foreign stock markets. With both literatures pointing towards the role of information in explaining agents' share of foreign assets (e.g. Abel et al. (2007) and Veldkamp and Van Nieuwerburgh (2010)), I move one step back and look at the role of information in explaining agents' entry decision in foreign stocks markets. Is there a role for information acquisition on the entry decision? Are agents inattentive in their investment decisions once they invest in foreign stocks? Empirical evidence seems confirm that information is indeed important in explaining agents' decision to enter the foreign stocks market. Agents rebalance their portfolio only infrequently, and rely on different sources of information in order to decide on their investments. In addition, households that hold foreign stocks appear to be more informed than households that hold only domestic assets. ${ }^{2}$

In this paper, I build from Abel et al. (2007)'s model and incorporate information on agents' portfolio allocation decision. In the model, in order to observe the value of their wealth, consumers have to pay an "observation cost". Because it is costly to observe the value of their wealth, consumers optimally choose to update their information set and their investment portfolio only infrequently. Departing from Abel et al. (2007), in the model, agents can invest not only in riskless asset and domestic stocks, but also in foreign stocks. The model shows that agents that invest in foreign stocks are more attentive, updating their portfolio more frequently. Although it is costly to obtain information, once increasing the overall share of stocks in their total portfolio, risk averse agents gain from diversification, but also face larger risks, and hence, they update their information set more frequently.

To account for the large share of the population that do not own domestic or foreign stocks, I further introduce a one-time entry cost out of agents' first-period wealth, to be paid if agents opt to

\footnotetext{
${ }^{1}$ For a review of the literature on participation puzzle see Campbell (2006) and Lewis (1999).

${ }^{2}$ Section 5 provides some empirical evidence on the role of information on household holdings of foreign stocks. See Nechio (2010) for a complete description on household holdings of foreign stocks.
} 
invest in stocks. This cost represents financial and time costs spent with learning about investment opportunities and acquire information about risks and returns. After calibrating the model to match returns and volatility for the U.S. economy and several foreign stock investments, I ask what would be the minimum entry cost needed to drive households out of stock markets. In particular, I assess the two minimum costs that, respectively; $(i)$ would drive agents out of the domestic market; (ii) or out of the foreign market once they already invest in domestic stocks. In line with the equity premium puzzle literature, the minimum entry cost needed to drive agents out of domestic stock markets is very large. ${ }^{3}$ More interestingly, if the entry cost is to be paid only for those who also invest in foreign stocks, this minimum entry cost is much smaller. Once agents already invest in domestic stock markets, the minimum cost that would drive investors out of foreign stocks market is also dependent on assets returns and their cross-correlation, and decreases with risk aversion and updating costs. Variations on risk aversion or uncertainty about foreign stocks returns can bring this latter minimum entry-cost down enough to rationally justify the large non-participation in foreign stock markets.

The empirical evidence confirms the model predictions. The Survey of Consumer Finances shows that agents that invest in foreign stocks are more sophisticated in their sources of information and more attentive. Households that invest in foreign stocks talk to financial advisers more frequently and use internet as a main source of information. In addition, they have higher willingness to take risks. Data from the Investment Company Institute point in the same direction, highlighting the roles of learning from experimenting with investment funds and using internet for information acquisition.

This paper relates to the literature about portfolio decision and inattention, in which Abel et al. (2007) introduce an information update cost into agents problem, Huang and Liu (2007) assume that agents can extract a signal from asset returns and analyze how information processing affects their portfolio decision, and Veldkamp and Van Nieuwerburgh (2010) look at optimal amount of information to acquire and the share of foreign assets agents hold in their portfolio. This paper also relates to the literature on households' portfolio and the participation puzzle. The latter literature is quite vast with a substantial documentation and analysis of household portfolios available at a collection of papers presented in Guiso et al. (2002). A highly studied candidate for such low participation is the presence of participation costs; however, the literature shows that only participation costs are not enough to account for the large fraction of the population that remains out of the stock market. Vissing-Jorgensen (2003) and Attanasio and Vissing-Jorgensen (2003) explore the role transaction costs in addition to participation costs and large risk aversion; Curcuru et al. (2009) introduces a short-sale constraint as an additional source of limitation to participation. Recent papers incorporate information as agents' driver to participate in stocks market, such as Guiso and Japelli (2005). Finally, this work also relates to the classic papers such as Merton (1969, 1971 and 1973) and Samuelson (1969), where agents take positions in all assets available and the portfolio shares are constant over the life-cycle, and to Baumol (1952) and Miller and Orr (1966) that look at the effects of transaction costs in cash-in-advance models

\footnotetext{
${ }^{3}$ For more on the equity premium puzzle literature see Mehra and Prescott (1985).
} 
(as in their model, agents hold cash to finance consumption between "updating" periods, when they remain inactive)

The aforementioned model is described in Sections 2 and 3. In Section 2, I introduce foreign stocks on the portfolio of financial assets of inattentive investors. The section presents the solution of the model and assesses its qualitative predictions. In Section 3, I slightly modify the model by assuming that before entering the stock market, agents have to pay a cost out of their initial wealth. The comparison between the value functions attained with three different portfolios, that are composed of: (i) only riskless assets; (ii) riskless assets and domestic stocks; (iii) riskless assets and both domestic and foreign stocks; yields the two types of minimum entry costs that would drive agents out of domestic stock markets, or out of foreign stock markets once they already invest in domestic stocks. Section 4 assesses the qualitative and quantitative predictions of the entry-cost model. Firstly, agents that own foreign stocks in addition to domestic ones update their portfolio more frequently than holders of domestic stocks only. After calibrating returns and volatilities of domestic and foreign stocks in accordance with data evidence, the model shows that the entry costs vary with asset returns, and decreases with the information updating cost and risk aversion. In Section 5 I provide some empirical evidence about household foreign holdings and the role of information. The data shows that household holding of foreign stocks is quite limited and the section provides evidence about the positive relation between foreign holdings and information variables. Agents that hold foreign stocks are more sophisticated in their sources of information and reportedly less risk averse. The data also points to the role of stock investment gains and losses in determining participation decision. Finally, in Section 6, I summarize the results and present the concluding remarks.

\section{The model - Costly Information}

Abel et al. (2007) build a model where inattentive investors update portfolio only sporadically and, in order to observe the value of their wealth, consumers must pay a cost that is proportional to the contemporaneous value of their wealth. Hence, consumers optimally choose to update their information set only at equally spaced points in time, and consume from a transaction account between "observation" periods. The authors show that even an observation cost as small as $0.01 \%$ is enough to generate an eight-month decision interval.

In the following sections, I depart from their paper in two directions: I first introduce foreign stocks on agents' portfolio choice, and then, I discuss the role of information and entry cost in such market.

In the model, consumer's wealth is held in an investment portfolio and in a riskless liquid asset for transactions. If she decides to enter the stock market, the investment portfolio is composed of a riskless bond and risky stocks, domestic and foreign. To observe the value of her wealth and portfolio of assets, the consumer pays a fixed cost, proportional to the wealth' contemporaneous value. Hence, it is optimal for the consumer to check her investment portfolio only infrequently, consuming from a riskless transactions account in the interim. For simplicity, in order to make constant the share held in 
each type of asset, I follow Abel et al. (2007) and assume that a manager continuously rebalances the portfolio within observation dates. ${ }^{4}$

The consumer maximizes:

$$
E_{t} \int_{0}^{\infty} \frac{1}{1-\alpha} c_{t+s}^{1-\alpha} e^{-\rho s} d s
$$

where $c$ stands for consumption, $0<\alpha \neq 1$ is the inverse of the intertemporal elasticity of substitution, and $\rho>0$ is the intertemporal rate of discount.

The investment portfolio is composed of a riskless bond that pays constant rate of return $r>0$, and of non-dividend-paying domestic and foreign stocks with prices $D_{t}$ and $F_{t}$, respectively, with $P_{t}=\left(\begin{array}{c}D_{t} \\ F_{t}\end{array}\right)$ following a geometric Brownian motion:

$$
\begin{aligned}
\frac{d P_{t}}{P_{t}} & =\mu d t+\sqrt{\Omega} d Z \\
\mu & >R
\end{aligned}
$$

where:

$$
\begin{aligned}
& \mu=\left(\begin{array}{c}
\mu_{d} \\
\mu_{f}
\end{array}\right), R=\left(\begin{array}{l}
r \\
r
\end{array}\right) \\
& \Omega=\left(\begin{array}{cc}
\sigma_{d}^{2} & \sigma_{d f} \\
\sigma_{d f} & \sigma_{f}^{2}
\end{array}\right),
\end{aligned}
$$

and $Z$ is a Wiener process, $\mu_{d}$ and $\mu_{f}$ are the returns on domestic and foreign stocks, respectively, and $\Omega$ is the variance-covariance matrix of stocks returns.

The consumer can observe the investment portfolio by paying a fraction $\theta, 0 \leq \theta<1$, of the contemporaneous value of the wealth. ${ }^{5}$ She can only withdraw funds from the portfolio if she observes the value. She also holds a riskless liquid asset that pays $r^{L}$, with $0 \leq r^{L}<r$, to finance consumption.

Let $t_{j}, j=1,2,3, \ldots$, be the times at which consumer observes the value of her portfolio. At time $t_{j}$, she chooses: (i) the next "observation date", $t_{j+1}=t_{j}+\tau$; (ii) the amount of the riskless liquid asset, $X_{t_{j}}(\tau)$, to finance consumption from $t_{j}$ to $t_{j+1}$; (iii) and the shares $\phi=\left(\begin{array}{c}\phi_{d} \\ \phi_{f}\end{array}\right)$ invested in domestic, $\phi_{d}$, and foreign stocks, $\phi_{f}$.

From time $t_{j}$ to $t_{j}+\tau$, the amount of riskless asset to finance consumption is:

$$
X_{t_{j}}(\tau)=\int_{0}^{\tau} c_{t_{j}+s} e^{-r^{L} s} d s
$$

and since $r^{L}<r$, when observation time arrives, the value in the riskless asset will have reached zero, i.e., $X_{t_{\tau}}=0$. At this time, the consumer pays the observation cost and observes the value of her wealth,

\footnotetext{
${ }^{4}$ Assuming continuous rebalancing substantially simplifies the solution. Duffie and Sun (1990) work on a version of the model with transaction costs, and instead assume that interest payments are reinvested in bonds and dividends are reinvested in equity.

${ }^{5}$ Assuming the observation cost as a fraction of the value of the portfolio allows one to obtain a closed form solution for the consumer's optimization problem. Gabaix and Laibson (2002) instead assume the observation cost to be constant in terms of utility and obtain an approximate solution for the consumer's problem.
} 
that after paying such cost equals:

$$
W_{t_{j+\tau}}=(1-\theta)^{\prime}\left(W_{t_{j}}-X_{t_{j}}\right) R\left(t_{j}, t_{j}+\tau\right)
$$

where $\mathcal{R}\left(t_{j}, t_{j}+\tau\right)$ is the gross rate of return to investment from time $t_{j}$ and $t_{j}+\tau$, and $\mathcal{R}\left(t_{j}, t_{j}\right)=1$.

For simplicity, I follow Abel et al. (2007) and also assume that a portfolio manager continuously rebalances the portfolio to maintain fixed the proportion of assets invested in stocks. In this case, the portfolio return follows a geometric Brownian motion;

$$
\frac{d \mathcal{R}\left(t_{j}, t_{j}+s\right)}{\mathcal{R}\left(t_{j}, t_{j}+s\right)}=\left[r+\phi^{\prime}(\mu-R)\right] d s+\phi^{\prime} \sqrt{\Omega} d Z .
$$

To solve the consumer's problem, I divide the problem in four steps: the consumption choice between two consecutive observation dates; the choice of riskless asset and the share invested in stocks; and two final steps that uncover the value function, and the optimal observational frequency. Proposition 1 highlights the main results from the model's solution. For details on the derivations and proposition proofs, I refer the reader to the Appendix to this paper.

Proposition 1 The solution to the consumer's problem implies that:

a. The value function is such that:

$$
V(W)=\gamma(\tau) \frac{W^{1-\alpha}}{1-\alpha}
$$

where:

$$
\gamma(\tau)=\left[\frac{1-e^{-\omega \tau}}{1-\chi e^{-\lambda \tau}}\right]^{\alpha} \omega^{-\alpha}
$$

b. The optimal shares held in domestic and foreign stocks equal:

$$
\phi^{*}=\frac{1}{\alpha} \Omega^{-1}(\mu-R)
$$

c. And the consumer optimally chooses to observe and update her portfolio at time $\tau^{*}$, obtained from solving:

$$
\frac{(\omega-\lambda)}{\omega} e^{-\lambda \tau^{*}}+\frac{\lambda}{\omega} e^{(\omega-\lambda) \tau^{*}}-\frac{1}{\chi}=0
$$

A second order approximation to this equation yields:

$$
\hat{\tau}^{*}=\left(\frac{2\left(\chi^{-1}-1\right)}{(\omega-\lambda) \lambda}\right)^{\frac{1}{2}}
$$

where $\chi=(1-\theta)^{\frac{(1-\alpha)}{\alpha}}, \omega=\frac{\left(\rho-(1-\alpha) r^{L}\right)}{\alpha}$ and $\lambda=\frac{\rho-(1-\alpha)\left(r+\frac{1}{2} \frac{1}{\alpha}(\mu-R)^{\prime} \Omega^{-1}(\mu-R)\right)}{\alpha}{ }^{6,7}$

\footnotetext{
${ }^{6}$ I follow Abel et al. (2007) and assume both $\omega>0$ and $\lambda>0$ to obtain a unique solution.

${ }^{7}$ When there is no observation cost, $\theta=0$ and the investor can freely update at every period. She optimally chooses to do so, and from the definition of $\chi$, one obtains $\theta=0 \Rightarrow \hat{\tau}=0$.
} 


\subsection{Model Predictions}

This section works through a set of model predictions about the optimal shares invested and the optimal level of inattention. For analytical proofs of the propositions, I refer the reader to the Appendix to this paper.

In Abel et al. (2007), domestic stocks are the only risky assets available, and since $\mu_{d}>r$, agents optimally choose to hold a positive share of their portfolio in stocks. Once agents can also invest in foreign stocks, and in principle explore the gains from asset return correlations, the share invested in one or the other type of stock can be negative, i.e., investors can optimally choose to short-sell one or the other asset ( $\phi_{d}$ or $\phi_{f}$ can attain negative values). However, since $\mu>R$, agents will still optimally choose to invest in stocks, and as Proposition 2 shows, the total share invested in stocks is positive.

Proposition 2 As long as $0<\mu-R<1$, the total share invested in stocks is positive, even though the share invested in one or the other can be negative.

$$
\phi_{d}+\phi_{f}>0
$$

Abel et al. (2007) also show that the optimal inattention increases with the updating $\operatorname{cost}\left(d \tau_{d}^{*} / d \theta>0\right)$, increases with the level of the risk-free rate $\left(d \tau_{d}^{*} / d r^{L}>0\right)$, decreases with the return on stocks $\left(d \tau_{d}^{*} / d \mu_{d}<0\right)$, and increases with the volatility of stocks returns $\left(d \tau_{d}^{*} / \sigma_{d}^{2}>0\right)$, for $\alpha>1 .^{8}$ The next set of propositions assesses how the model performs, once foreign stocks are made available to consumers.

Proposition 3 The optimal inattention increases with the updating cost and increases with the level of the risk-free rate (regardless the availability of foreign stocks);

$$
\frac{\partial \tau^{*}}{\partial \theta}>0, \frac{\partial \tau^{*}}{\partial r^{L}}>0
$$

Since short selling is possible, the effects of return and variance on optimal inattention are undetermined. As the following proposition proves, however, once a non-short-selling constraint is imposed, one obtains unequivocal predictions for such effects.

Proposition 4 If $\alpha>1$, and non-short-selling is assumed, i.e., $\phi_{d}>0$ and $\phi_{f}>0$, the optimal level of inattention is negatively correlated with mean returns on domestic and foreign stocks, positively correlated to the volatility of those assets' returns, and positively correlated to the covariance of such

In this case, we are back to the classic Merton (1969) model where agents have no cost of observing or adjusting their portfolio and choose the share invested in stocks to be constant and independent of wealth. The optimal share invested in each type of stock is the same as in his model when generalized for many assets.

${ }^{8}$ For an analytical proof of these results, please refer to Propositions 1, 2 and 3 of Abel et al. (2007). 
returns:

$$
\begin{aligned}
\frac{\partial \tau^{*}}{\partial \mu_{d}} & <0, \frac{\partial \tau^{*}}{\partial \mu_{f}}<0 \\
\frac{\partial \tau^{*}}{\partial \sigma_{d}^{2}} & >0, \frac{\partial \tau^{*}}{\partial \sigma_{f}^{2}}>0 \\
\frac{\partial \tau^{*}}{\partial \sigma_{d f}} & >0 .
\end{aligned}
$$

The larger are the mean stock returns, $\mu_{d}$ and $\mu_{f}$, and the smaller are the returns variance, $\sigma_{d}^{2}$ and $\sigma_{f}^{2}$, the smaller is consumer's inattention. Both results are driven by the fact that once returns are larger and volatility is smaller, agents tilt their portfolio towards more holdings of stocks, increasing the "risky share" of assets, and hence, they need to update their information more frequently.

\section{The participation decision - entry-cost model}

While the model of Section 2 predicts to be optimal for all agents to always invest in stocks, empirical evidence points to a large fraction of households out of the stock market (Section 5 will also confirm this low participation when looking at household data).

Hence, in this section, I look at agents' decision to enter the domestic and foreign stock markets. I consider two cases; first I look at the decision to enter the domestic stocks market, when foreign stocks are not available, and next, I consider the case where agents invest in domestic stocks and decide on whether to also invest in foreign ones. ${ }^{9}$

To account for the non-participation observed in household data, I assume that in addition to the updating $\operatorname{cost} \theta$, agents pay a one-time entry $\operatorname{cost} K$, out of their initial wealth, to enter the stock market. This entry cost represents financial and time costs spent on learning about investment opportunities, acquiring information on risks and returns, and any type of brokerage commissions. ${ }^{10}$ I consider the two cases described above and assess the two minimum costs $K_{d}$ and $K_{f}$ that, respectively; $(i)$ would drive agents out of the domestic market; $(i i)$ or out of the foreign market once they already invest in domestic stocks.

The exercise, hence, comprises the comparison of three value functions; the first arises from the case where agents do not invest in stocks, the second corresponds to the value function attained by the investor that only invests in domestic stocks; and the third is the value function of an agent that invests in both domestic and foreign stocks (as in equation (3)).

\footnotetext{
${ }^{9}$ The empirical evidence shows that it is almost never the case where agents invest directly in foreign stocks but not in domestic ones.

${ }^{10}$ Jones (2002) documents a large decline in such commissions charged by brokerages firms.
} 


\subsection{No participation in stocks markets}

If agents opt not to enter the stock market and hold all their wealth in the riskless liquid asset, their overall rate of return equals $r^{L}$. From the definitions of $\lambda, \omega$ and $\gamma(\tau)$ in Proposition 1 , the non-entry decision implies: $\lambda=\omega$ and $\gamma(\tau)=\omega^{-\alpha}$. Hence, her value function, at time 0 , equals: ${ }^{11}$

$$
V\left(W_{0}\right)=\omega^{-\alpha} \frac{W_{0}^{1-\alpha}}{1-\alpha}
$$

\subsection{Participation in domestic stocks markets only}

Now assume agents only have domestic stocks as of risky assets available. To invest in domestic stocks they pay an entry cost $K$, out of their first period wealth. I then ask what would be the minimum value of the entry cost, $K_{d}$, that would drive agents out of the domestic market.

In order to answer this question, I exclude foreign stocks from the model. The solution of such a model is similar to the one obtained in Proposition 1, and replicates exactly the one extensively described in Abel et al. (2007). Since most of the equations of both models with and without foreign stocks are isomorphic, to refer to the case where agents only invest in domestic stocks, I add a subscript " $d "$ to all variables that refer to this case.

Hence, for the case where consumers invest only in domestic stocks, the value function, the optimal share invested in stocks, and the optimal inattention are such that: ${ }^{12}$

$$
\begin{gathered}
V(W)=\gamma_{d}(\tau) \frac{W_{0}^{1-\alpha}}{1-\alpha} \\
\phi=\phi_{d}=\frac{1}{\alpha} \frac{\left(\mu_{d}-r\right)}{\sigma^{2}} .
\end{gathered}
$$

And $\tau_{d}^{*}$ maximizes:

$$
\frac{\left(\omega-\lambda_{d}\right)}{\omega} e^{-\lambda_{d} \tau_{d}^{*}}+\frac{\lambda_{d}}{\omega} e^{\left(\omega-\lambda_{d}\right) \tau_{d}^{*}}-\frac{1}{\chi}=0 .
$$

A second order approximation to this last equation yields:

$$
\hat{\tau}_{d}^{*}=\left(\frac{2\left(\chi^{-1}-1\right)}{\left(\omega-\lambda_{d}\right) \lambda_{d}}\right)^{\frac{1}{2}}
$$

\footnotetext{
${ }^{11}$ Recall that under the assumptions imposed in the parameters of Subsection 2, it is optimal for the investor to enter the stock market and invest on both type of stocks. It is also optimal to observe and update the portfolio at equally spaced points of time.

${ }^{12}$ The following equations can be obtained by eliminating foreign stocks from the model presented in Subsection 2 , and I refer the reader to Abel et al. (2007) for a full description of their solution.
} 
where:

$$
\begin{aligned}
\gamma_{d}(\tau) & =\left[\frac{1-e^{-\omega \tau_{d}}}{1-\chi e^{-\lambda_{d} \tau_{d}}}\right]^{\alpha} \omega^{-\alpha} \\
\lambda_{d} & =\frac{\rho-\left[(1-\alpha)\left(r+\frac{1}{2} \frac{1}{\alpha} \frac{\left(\mu_{d}-r\right)^{2}}{\sigma_{d}^{2}}\right)\right]}{\alpha} .
\end{aligned}
$$

Therefore, the minimum $K_{d}$ needed to drive agents out of the domestic stocks market is such that it equals the value functions of consumers that invest in domestic stocks (equation (8) after paying the entry cost), and consumers who do not invest in stocks at all (equation (7)), i.e.:

$$
\gamma_{d}(\tau) \frac{\left(W_{0}\left(1-K_{d}\right)\right)^{1-\alpha}}{1-\alpha}=\omega^{-\alpha} \frac{W_{0}^{1-\alpha}}{1-\alpha}
$$

where $\gamma_{d}(\tau)$ defined as in (9). This yields:

$$
K_{d}=1-\left(\frac{1-e^{-\omega \tau_{d}}}{1-\left[(1-\theta)^{\frac{(1-\alpha)}{\alpha}}\right] e^{-\lambda_{d} \tau_{d}}}\right)^{\frac{-\alpha}{1-\alpha}} .
$$

\subsection{Participation in foreign stocks market}

The empirical evidence shows an even smaller share of agents choose to invest in foreign stocks, even among those who already invest in domestic stocks (see Section 5). Hence, I ask what would be the minimum entry cost, $K_{f}$, that would drive agents out of foreign market, once they already invest in domestic stocks. For this case, I assume agents pays no entry cost to invest in domestic stocks, but to also invest in foreign markets they pay an extra entry cost. The minimum entry cost $K_{f}$ that would drive agents out of foreign markets is obtained by comparing the value functions in equations (3) and (8):

$$
\left[\frac{1-e^{-\omega \tau}}{1-\left[(1-\theta)^{\frac{(1-\alpha)}{\alpha}}\right] e^{-\lambda \tau}}\right]^{\alpha} \omega^{-\alpha} \frac{\left(W_{0}\left(1-K_{f}\right)\right)^{1-\alpha}}{1-\alpha}=\left[\frac{1-e^{-\omega \tau_{d}}}{1-\left[(1-\theta)^{\frac{(1-\alpha)}{\alpha}}\right] e^{-\lambda_{d} \tau_{d}}}\right]^{\alpha} \omega^{-\alpha} \frac{W_{0}^{1-\alpha}}{1-\alpha},
$$

where the left hand side corresponds to equation (3), and the right hand side corresponds to the analogous function for an agent that only invest in domestic stocks, equation (8).

The equality above uncovers $K_{f}$ that equals:

$$
K_{f}=1-\left(\frac{\frac{1-e^{\omega \tau} d}{1-\left[\left(1-\theta_{d}\right)^{\left(\frac{(1-\alpha)}{\alpha}\right.}\right] e^{-\lambda_{d} \tau^{2}}}}{\frac{1-e^{\omega \tau}}{1-\left[(1-\theta)^{\frac{(1-\alpha)}{\alpha}}\right] e^{-\lambda \tau}}}\right)^{\frac{\alpha}{1-\alpha}} .
$$




\section{Entry-cost-model predictions}

\subsection{Implications on the optimal level of inattention}

Proposition 5 shows that the introduction of foreign stocks into the model implies agents updating their portfolio more frequently (assuming $\alpha>1$ ). As Section 5 will show, this theoretical result also has empirical support.

Proposition 5 If $\alpha>1$, the (approximately) optimal level of inattention is smaller once foreign stock holdings is introduced into the model, i.e.:

$$
\hat{\tau}^{*}<\hat{\tau}_{d}^{*}
$$

Section 4.2 complements the model predictions by calibrating the parameters and inferring on the relation between such parameters, the cost $K_{f}$ and the optimal information adjustment process.

\subsection{Assessing the level of fixed costs that justify non-participation}

To parameterize the model and to quantify the effects of foreign stocks on optimal inattention $\tau$ and $K_{f}$, I follow Abel et al. (2007), and assume $\alpha=4, \rho=0.01, r^{L}=0.01, r=0.02$. In order to calibrate for asset returns and correlations, I use data from Morgan Stanley Capital International (MSCI) that provides stock market returns for different countries and regions, besides the United States. ${ }^{13}$

For all indices, I use before-tax returns on stocks at a monthly frequency, which are further annualized. In particular for the U.S., I obtain return and volatility of the $S \& P 500$, that correspond respectively to $\mu_{d}=0.086$ and $\sigma_{d}^{2}=(0.17)^{2}$. Under these assumptions for return and volatility of domestic stocks, the optimal inattention predicted by a version of the model without foreign stocks (as in Section 3.2 and Abel et al. (2007)) equals $\hat{\tau}_{d}^{*}=0.47$ years, and the share invested in stocks equals 0.43. Under this version of the model, the entry cost necessary to drive agents out of the domestic stock market is $K_{d}=0.78$, i.e., to justify non-participation in domestic stocks markets, the minimum entry-cost needed reaches $78 \%$ of their initial wealth.

Once consumers have the option to also invest in foreign stocks, one has to make a stand about returns and volatilities of such a market, and about the covariance of foreign stocks with domestic ones. As a proxy for foreign returns, I look at several foreign stock indices: the "EAFE", that comprehends returns to stocks in Europe, Australasia and Far East; ${ }^{14}$ "Europe" corresponds to stocks in developed economies in Europe; ${ }^{15}$ "Japan" and "Canada" are composed of stocks from these two countries,

\footnotetext{
${ }^{13}$ In particular, I use gross total returns of MSCI Global Standard Indices, which aggregates large and mid-capitalized company returns from January 1970 to January 2010.

${ }^{14}$ The MSCI EAFE Index consists of the following 21 developed-countries indices: Australia, Austria, Belgium, Denmark, Finland, France, Germany, Greece, Hong Kong, Ireland, Italy, Japan, the Netherlands, New Zealand, Norway, Portugal, Singapore, Spain, Sweden, Switzerland, and the United Kingdom.

${ }^{15}$ MSCI Europe Index consists of the following 16 developed-countries indices: Austria, Belgium, Denmark, Finland, France, Germany, Greece, Ireland, Italy, the Netherlands, Norway, Portugal, Spain, Sweden, Switzerland, and the United Kingdom.
} 
respectively; and "Emerging Markets" comprehend stocks from emerging market economies. ${ }^{16}$

Table 1 reports annualized logarithmic returns, volatilities and covariances for the foreign-countries indices underneath column "Parameters". Under "Model Predictions", the Table also provides the results obtained for the optimal inattention $\hat{\tau}^{*}$, the minimum entry cost $K_{f}$, and the implied shares invested in each type of index, $\phi_{d}, \phi_{f}$.

Table 1: Illustrative Calculations

\begin{tabular}{lcccccccc}
\hline \hline & \multicolumn{3}{c}{ Parameters } & & \multicolumn{3}{c}{ Model Predictions } \\
\cline { 2 - 3 } EAFE & $\mu_{f}$ & $\sigma_{f}^{2}$ & $\sigma_{d f}$ & & $\hat{\tau}^{*}$ & $K_{f}$ & $\frac{\phi_{f}}{\phi_{d}+\phi_{f}}$ \\
Europe & 0.096 & $(0.172)^{2}$ & 0.016 & & 0.37 & 0.24 & 0.61 \\
Japan & 0.101 & $(0.175)^{2}$ & 0.018 & & 0.36 & 0.25 & 0.67 \\
Canada & 0.093 & $(0.217)^{2}$ & 0.012 & & 0.40 & 0.17 & 0.38 \\
EmergingM. & 0.097 & $(0.203)^{2}$ & 0.024 & & 0.43 & 0.09 & 0.43 \\
\hline \hline
\end{tabular}

Confirming Proposition 5, Table 1 shows that inattention is smaller when agents also invest in foreign stocks as the column labeled as $\hat{\tau}^{*}$ indicates - agents that also invest in foreign stocks, optimally choose to update their portfolio at a higher frequency. The column labeled as $K_{f}$ shows that when compared to $K_{d}=0.78$, the minimum entry cost needed to drive agents out of the foreign market, once they already invest in domestic stocks, are relatively small, but possibly large enough to feed the non participation in foreign markets puzzle - for Europe as an example, the share of wealth necessary to drive agents out of foreign stocks once they already invest in domestic ones reaches as high as $25 \%$.

The large number attained by $K_{d}$ is in line with the equity premium puzzle predictions. In order to justify the large non-participation in domestic stocks markets, the level of frictions should be large enough implying a high level of entry cost, as in this model, or a high level of risk aversion, as posed by the equity premium puzzle literature. The possibly high entry cost needed to drive agents out of the foreign stocks market, however, is a intriguing new fact, given the substantial non-participation in foreign markets.

To give sense for the latter cost, and to test for the sensitivity of the results, in the next section, I vary some of the main parameters and observe the effects on the entry cost and the inattention levels.

\subsection{Sensitivity analysis}

Table 1 shows that the entry cost needed to drive agents out of foreign stock markets once they already invest in domestic stocks is much smaller than $K_{d}=0.78$, but for the exemplified stock indices, it can range from $9 \%$ for Canada stocks to $25 \%$ for European stocks. The inattention level also varies from 0.36 to 0.46 for the same stock indices.

\footnotetext{
${ }^{16}$ The MSCI Emerging Markets Index consisted of the following 22 emerging-markets indices: Brazil, Chile, China, Colombia, Czech Republic, Egypt, Hungary, India, Indonesia, Israel, Korea, Malaysia, Mexico, Morocco, Peru, Philippines, Poland, Russia, South Africa, Taiwan, Thailand, and Turkey.
} 
In this section I test for the sensitiveness of these results by moving in two directions; I first look at the effects of varying the updating $\operatorname{cost}(\theta)$, and the risk aversion $(\alpha)$. For brevity, I focus on the case of investing in the U.S. and Europe, and U.S. and Canada by assuming stock returns and volatility equal to the U.S. ones for domestic stocks, and equal to Europe and Canada ones for foreign, as reported under the column "Parameters" in Table 1. I next assume stocks returns are the same for domestic and foreign stocks (and equal to the US ones) and vary assets correlation $\left(\rho_{d f}\right)$, the updating cost $(\theta)$, and the risk aversion $(\alpha)$.

While the first venue shows how sensitive the results are according to the choice of parameters, the second path builds on the findings of Calvet et al. (2007), who show that agents that enter the stock market, potentially invest inefficiently, obtaining returns that are smaller than those indicated by stock indices. In fact, Table 1 shows that the average returns on the different stock indices are somewhat similar, and not statistically different from each other, and hence, assuming equal returns in both foreign and domestic stock markets while varying $\rho, \theta$, and $\alpha$ does not seem as a big stretch, and is in line with the inefficiencies pointed by Calvet et al. (2007).

The results of these exercises are presented in Figures 1 to 3. The next subsections discuss the roles of each parameter variation.

\subsubsection{The role of the updating cost}

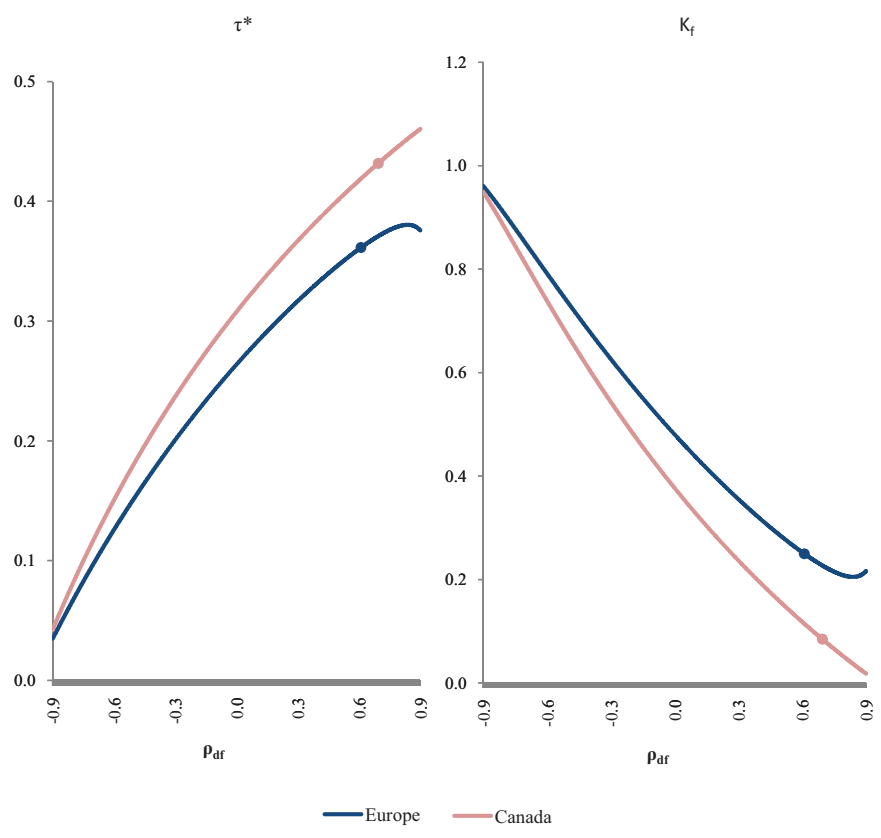

Figure 1: Optimal inattention and minimum entry-cost - Varying updating costs

Foreign stock investors have to not only inform themselves about the domestic stock market, but also about the foreign market. Hence, in this exercise, I deviate slightly from the model by assuming 
that agents that hold only domestic stocks pay $\theta=0.01 \%$ of their portfolio value to update their information set, but pay a higher rate once they also invest in foreign stocks. Hence, I depart from the benchmark assumptions and results of Table 1 and increase the updating cost for those agents that are holding foreign stocks. More specifically, when building $K_{f}$, as in equation (10), one compares the value associated with holdings of domestic stocks only with holdings of foreign ones. In this exercise, I am fixing the updating costs for domestic-only stock holders $\left(\theta_{d}\right.$ in the numerator of the term in parenthesis of equation (10)), and varying the updating cost associated with holdings of both foreign and domestic stocks $(\theta$ in the denominator of the term in parenthesis of equation (10)).

Figure 1 looks at the effects of the updating $\operatorname{cost} \theta$ on $\hat{\tau}^{*}$ and $K_{f}$. In this exercise, I assume asset returns and volatilities equal to the values reported in Table 1 the U.S. (home), Europe, and Canada (foreign), and I vary the updating cost, $\theta$, from $0.01 \%$ to $2 \%$. The two points highlighted on both curves in the two charts of Figure 1 (on the left-hand-side y-axis), correspond exactly to cases reported on Table 1 , when $\theta_{d}=\theta=0.01 \%$.

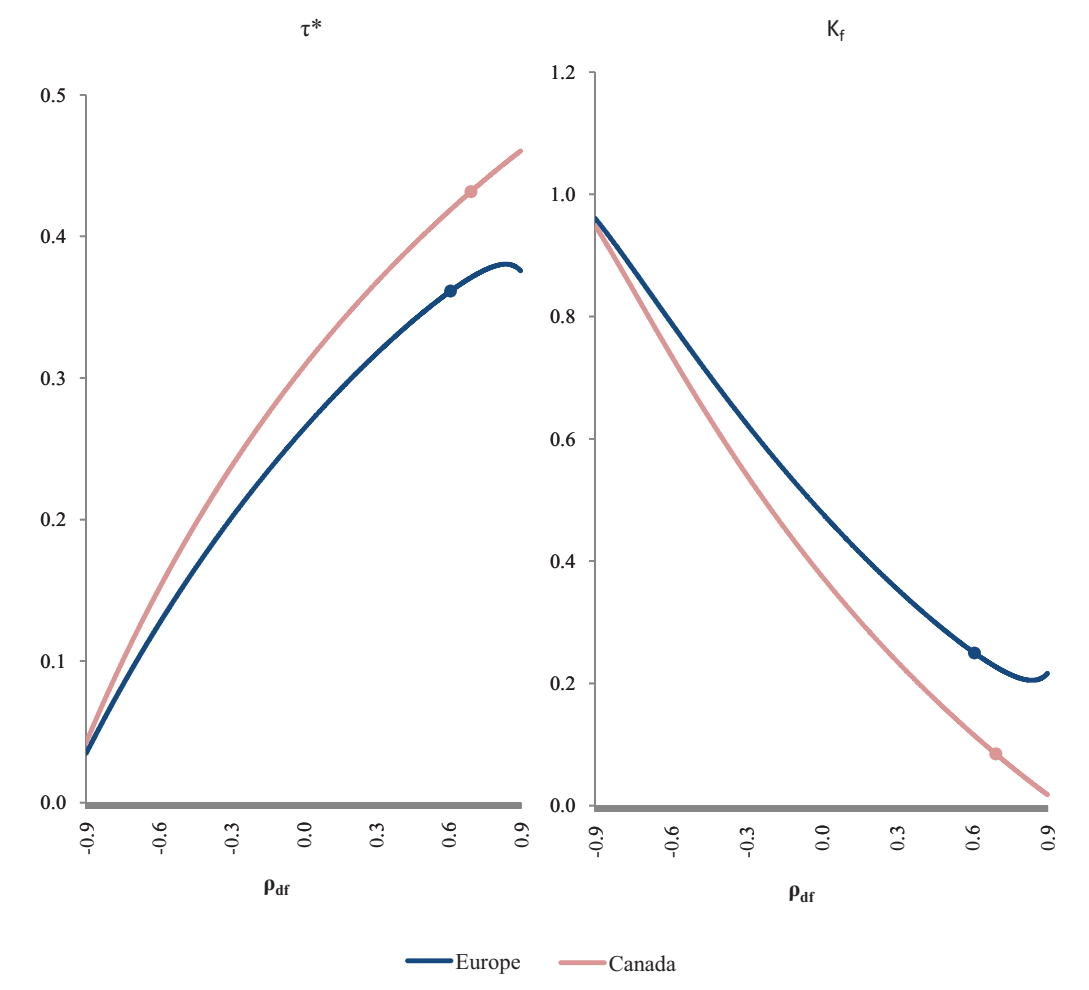

Figure 2: Optimal inattention and minimum entry-cost - Varying risk aversion

The two charts show that the larger is the updating cost $(\theta)$, the larger is the optimal inattention and the smaller is $K_{f}$. However the effects on $K_{f}$ of increasing $\theta$ are not too large. In fact, a fifty times larger updating cost moves the minimum entry-cost $K_{f}$ from $25 \%$ to $20 \%$ for Europe and from $9 \%$ to $4 \%$ for Canada. For the case of Europe, an updating cost as high as $1 \%$ of their portfolio value still 
requires an entry-cost of at least $15 \%$ to drive agents out of the foreign stocks market.

\subsubsection{The role of risk aversion}

The theoretical literature presents little agreement the level for the risk aversion parameter. While several papers assume logarithmic utility (approximating $\alpha$ to unity), several others assume larger values for such parameter. In this subsection, I also test for the sensitivity of the results to the risk aversion parameter. The risk-premium puzzle literature argues that the risk aversion needed to justify the large non-participation in stocks assets has to be quite large. So, I repeat the above exercises by fixing asset returns and volatilities as of the U.S., Europe and Canada, and varying the risk aversion parameter $\alpha$ from 2 to 6 .

Figure 2 shows that the larger the risk aversion (larger $\alpha$ ), the larger the optimal inattention. While this may look counter intuitive at first, the positive relation comes from the effect of $\alpha$ on the optimal share held of assets. The larger is the risk aversion, the smaller is the share of the portfolio held in stocks (both foreign and domestic), and hence, less frequently agents update their information set. Figure 11 shows that when moving $\alpha$ from 4 to 5 , the minimum cost needed to drive agents out of the foreign market drops from $25 \%$ to $17 \%$, for Europe and from $9 \%$ to $1 \%$ in Canada. ${ }^{17}$

\subsubsection{Asset returns}

Figures 1 and 2 showed the effects of some parameter assumptions on the levels of inattention and the minimum entry-cost. In particular, the exercises showed that while the effects of updating costs and risk aversion are significant, the minimum entry-cost needed to explain agents' non-participation in foreign stocks markets can be still relatively high to explain such large non-participation, especially for the case of the European stock index. The large and relatively invariant entry cost is mostly a result of the additional expected return assumed for European stocks. However, statistically, one cannot reject the equality between these U.S. and Europe returns, since the excess average return on stocks in Europe with respect to U.S. is not larger than its standard deviation. In fact, not only statistically they can not be set apart, but also, in line with Calvet et al. (2007), there is evidence that agents' investment decisions are inefficient, and the returns obtained by investors possibly do not reflect the overall gains they could attain. Following these two facts, I complement the analysis by assuming that mean return and volatility are the same for the stocks at home and foreign, and equal to the U.S. ones, and then repeat the two exercises reported on Figures 1 and 2 in addition to looking at the diversification effect. That is, while keeping foreign and domestic returns equal, I subsequently vary the assets correlation from -0.9 to 0.9 , vary the updating cost from $0.01 \%$ to $2 \%$, and vary the risk aversion from 2 to 6 . For brevity, I focus on the U.S. versus Europe case and assume $\sigma_{d f}=0.018$, when varying $\theta$ and $\alpha$. The results are reported in Figure 3, where in addition to the curves for optimal inattention and minimum entry-cost, for ease of comparison, each chart also marks the points that correspond to the benchmark parameter choices.

The first two charts on the top panel of Figure 3 show that while ranging the correlation of assets from -0.9 to 0.9 , the gains from diversification reduce substantially, and when correlation is the same

\footnotetext{
${ }^{17}$ Notice that varying risk aversion also affects $K_{d}$, but the effects are smaller than on $K_{f}$. $K_{d}$ ranges from 0.91 to 0.72 when I vary $\alpha$ from 2 to 6 .
} 
$\tau^{*}$
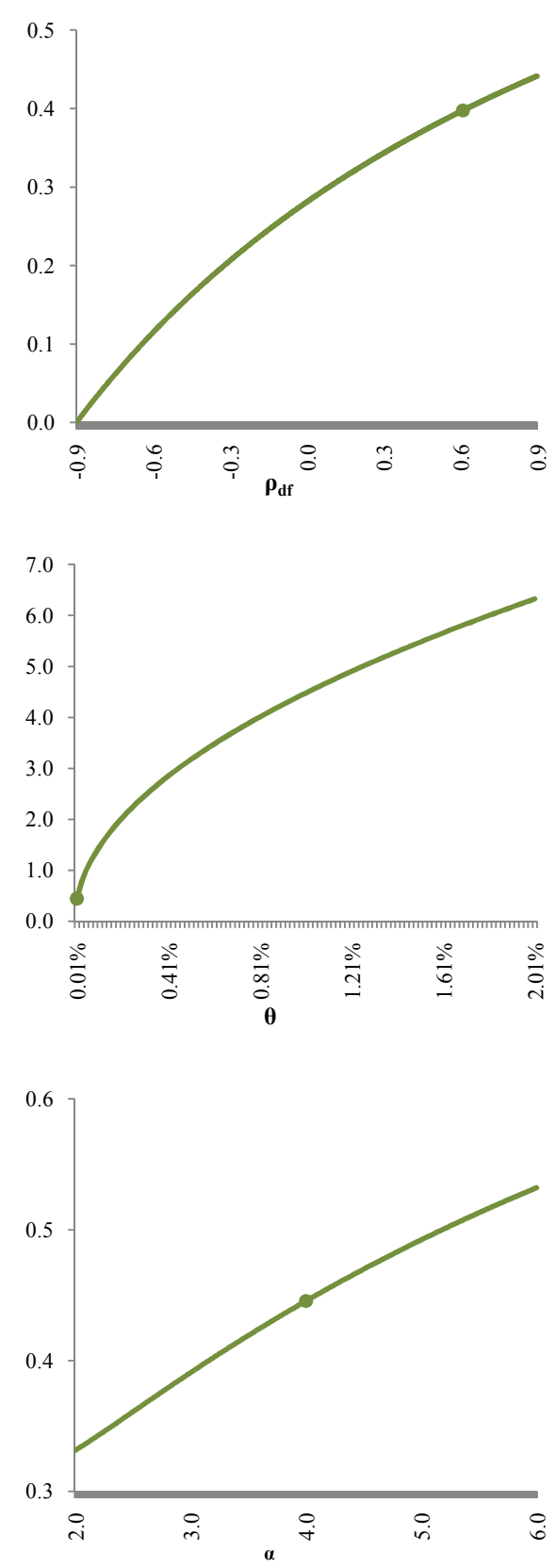

$K_{f}$
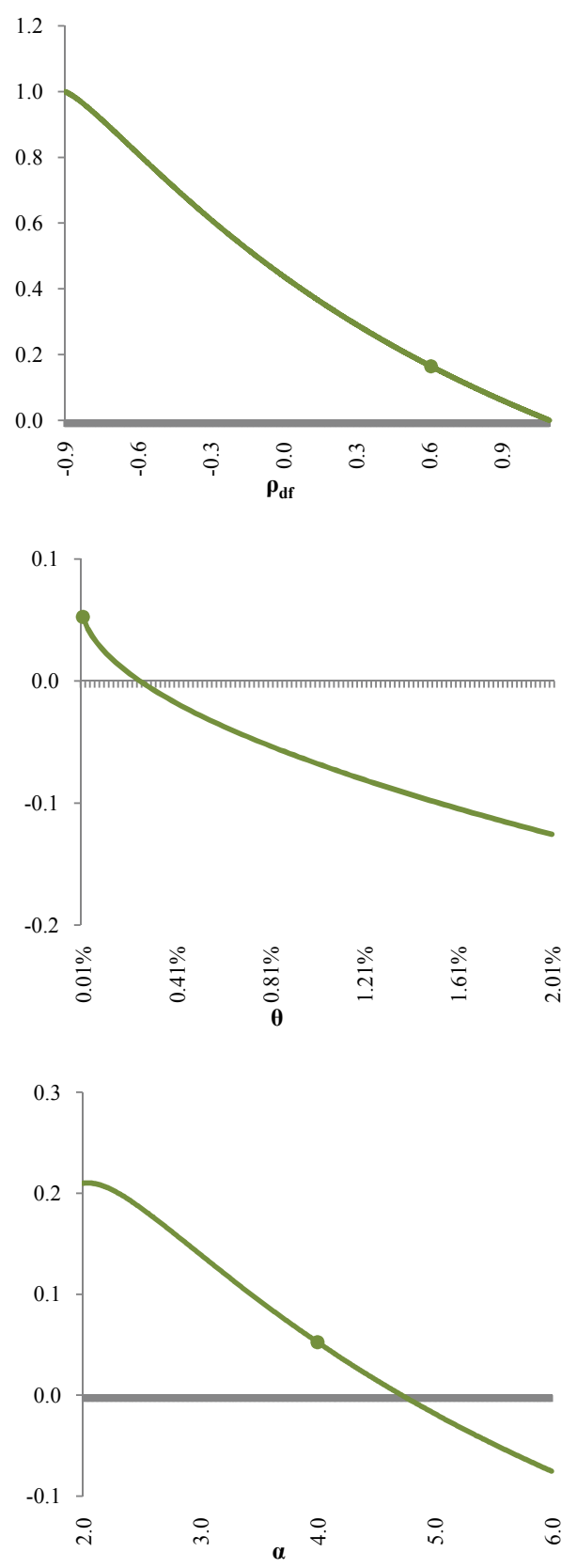

Figure 3: Optimal inattention and minimum entry-cost - Assuming equal returns and volatility 
as in the data $\left(\sigma_{d f}=0.018\right)$, the entry cost needed to drive agents out of foreign stocks once they already invest in domestic ones drop by a half, from $25 \%$ to $13 \%$. In addition, the middle panel charts show that when both foreign and domestic assets yield the same return and volatility, a $1 \%$ updating cost and an entry cost of $1 \%$ of initial wealth are already enough to justify non-participation in foreign stocks markets. Finally, if risk aversion is set at 5 instead of 4 , the minimum entry cost ranges on the negative side, showing that it is not profitable to invest in foreign stocks.

\section{Some empirical evidence}

In this section I provide some empirical evidence on participation in foreign stocks markets and the relation between the participation decision and information acquisition variables. The finance literature has focused on total holdings of stocks and the international finance literature has focused on share of foreign assets held, hence, the data presented here should be seen as complementing the information already provided in the literature. In particular, I will provide some empirical evidence of a positive correlation between information and the decision of participating in the financial markets.

I focus on two sets of data. The first corresponds to the Survey of Consumer Finances that consists of a survey on households across the U.S.. While this data set gains in comprehensiveness of its broad coverage and questionnaire, it only inquires about direct holdings of foreign stocks, i.e., foreign stocks held through brokerage accounts. Hence, I complement this data by also looking at evidence reported by the Investment Company Institute, that covers asset holdings in the investment funds industry.

The Survey of Consumer Finances consists of a triennial household survey on assets holdings in U.S. The survey interviews 3000 households randomly selected, and some additional 1500 high-wealth households selected from tax records. Since most of financial and non-financial assets are held by the wealthier individuals, this oversampling of wealthier households allows for a better description on households' portfolio, and make survey weights important to uncover statistics for the United States population. Therefore, all data and statistics from the $S C F$ in this paper are weighted. The Survey is a cross-sectional selection of randomly selected individuals every three years, and for this paper, I focus on the data for $2007 .^{18}$

I also rely on information provided by the Investment Company Institute $(I C I)$. The $I C I$ is a national association of U.S. investment companies including mutual funds, closed ended funds, exchange traded funds and unit investment trusts. They produce a series of reports on recent developments on the investment funds industry, in addition to sporadic surveys among fund investors. I use their

publications as a source of information with respect to indirect holdings of foreign assets, in order to shed some light on the recent developments of such class of assets on household's portfolios. Since the ICI reports comprise only the universe of investment fund holders, the data raises concerns about representativeness. Notwithstanding, the ICI data and reports provide an interesting summary of the recent trends on indirect stocks ownership, signaling towards a significant enlargement on agents' holdings of foreign stocks through investment funds.

\footnotetext{
${ }^{18}$ Nechio (2010) covers the SCF data from 1998 to 2007.
} 


\subsection{Limited participation}

The $S C F$ inquires about direct holdings of stocks. Firstly, it asks households whether they own stocks directly (through brokerage accounts), and subsequently it asks if among these holdings of stocks, the household also owns stocks from a company headquartered outside the U.S.. For simplicity, I build two classes of assets to correspond to the two aforementioned questions; Domestic and Foreign. Domestic refers to the share of agents that hold only domestic stocks outside investment funds (mainly through brokers or commercial banks), and do not hold foreign stocks directly. To build Domestic, I exclude from "direct holders of stocks" those who answered positively to the question about holdings of stocks from a company headquartered outside the U.S.. Foreign stocks holders correspond to those who answered positively to the question "Among your direct holdings of stocks, do you have stocks from a company headquartered outside the United States?". In principle, those agents can potentially be also holders of domestic stocks, or holders of foreign stocks through investment funds. ${ }^{19}$

The 2007 Survey of Consumer Finances shows that participation in foreign stock markets is indeed very limited. The percentage of the U.S. population that holds foreign stocks directly reaches as low as $3 \%$ in $2007 .{ }^{20}$ The analogous figure for domestic stocks holdings, that is, the percentage of the U.S. population that holds domestic stocks directly reaches $15 \%$ in 2007.

When looking at agents that hold investment funds, these numbers are substantially higher, but still much smaller than holdings of domestic stocks. A recent survey ran jointly by the $I C I$ and the Securities Industry Association shows that, while the direct ownership of foreign stocks has not increased a lot since 1999, the percentage of stock mutual fund investors owning international funds has increased substantially. The survey shows that among equity funds investors, $15 \%$ held foreign stocks directly in 1999, $18 \%$ in 2002 and $21 \%$ in 2005. Among mutual fund investors (bond and equity funds), the percentage of agents that also hold Global (International) Mutual Funds is $62 \%$ in 1999, 56\% in 2002 and $65 \%$ in $2005 .^{21,22}$

\subsection{Information and stock holdings}

Taking a closer look at the information provided by the $S C F$ in 2007, Table 2 compares non-holders of stocks to holders of domestic stocks, and holders of foreign stocks. It reports some statistics concerning information acquisition and holdings of stocks.

Education is a good proxy for information. Households with more years of schooling tend to be more informed, and if information is the variable preventing agents from taking advantage of the opportunities in the stock market, the higher the education level, the larger the participation in domestic and foreign stock markets.

The first row of Table 2 reports the mean number of education years for non-holder of stocks, holders

\footnotetext{
${ }^{19}$ The SCF does not answer if holders of foreign stocks are also holders of domestic ones. The ICI data set, however, indicates that this is indeed the case, and roughly every agent that holds foreign stocks directly also holds domestic ones.

${ }^{20}$ The same is true for other years that the Survey asked this question. Participation in foreign stocks ranges from $2.2 \%$ in 1998 to $2.83 \%$ in 2007 .

${ }^{21}$ The survey, Equity Ownership in America, was conducted in the first quarter of 2005 with 2414 equity investors (defined as owner of any type of equity).

${ }^{22} \mathrm{~A}$ back of envelope calculation merging information from both the SCF and the ICI would give that around $7 \%$ of households in the U.S. hold global mutual funds, since the SCF shows that as of 2007, $11 \%$ of agents had mutual funds.
} 
of domestic stocks only and holders of foreign stocks. The results show that agents that hold foreign stocks have more years of education. In fact, the $S C F$ also shows that participation in foreign stocks among college degree holders reaches $6 \%$ in 2007.

As of variables concerning information, households are also asked about the amount of "Shopping Around" they do when making investment decisions in a scale from 1 (no shopping for investments) to 5 (a great deal of shopping). ${ }^{23}$ Foreign stocks holders are the ones that shop around the most, followed by domestic investors and non-holders. Households also report the number of times they talked to their broker within the year for updating their stock investments, as the variable "Times" show. ${ }^{24}$ Holders of foreign stocks talk to their brokers much more often that holders of domestic stocks only. ${ }^{25}$ Finally, they are also asked their main source of information when investing. ${ }^{26}$ They can report many different sources and the variable "Internet" in Table 2 corresponds to the share of agents that report internet as a first main source. Stock investors report internet as a source of information for their investment decisions more often than non-holders. Foreign investors, however, consult internet even more frequently. ${ }^{27}$ Besides the information reported in the above tables, the survey also shows that the main sources of information are quite different for the different types of investors. Foreign stocks holders appear not only to consult internet more frequently but also use newspapers and brokers as major sources, while domestic stocks holders mostly consult friends and family as main sources of information.

\begin{tabular}{cccc} 
Table 2: Stock Holders versus & Non-holders & Informational varia \\
\hline \hline & Non-holder & Domestic & Foreign \\
Education years & 12.15 & 14.85 & 15.51 \\
Shopping for investment $^{a}$ & 2.74 & 3.19 & 3.29 \\
Times talk to broker $^{b}$ & 1.87 & 7.27 & 17.12 \\
Internet for investment & 19.19 & 39.67 & 57.24 \\
\hline \hline
\end{tabular}

${ }^{a}$ Self-reported degree of shopping for investments options

${ }^{b}$ Mean number of times talked to the broker

Source: Survey of Consumer Finances

Regarding information acquisition, the surveys and publications from the ICI reveals that around $65 \%$ of investors start their financial investments in stock markets through the purchase of investment funds. Among those, some will later migrate to individual stock holdings. In addition, with respect to internet usage, in fact, an ICI survey on mutual fund holders reports that between 2006 and 2009, an average of $90 \%$ of mutual fund investors have internet access. In addition, in $2009,82 \%$ of these investors

\footnotetext{
${ }^{23}$ The exact question corresponds to: "When making saving and investment decisions, some people shop around for the very best terms while others don't. What number would (you/your family) be on the scale? 1. Almost no shopping; 2. ; 3. Moderate shopping; 4. ; 5. A great deal of shopping"

${ }^{24}$ Households answer the question: "Over the past year, about how many times did you buy or sell stocks or other securities through a broker?"

${ }^{25}$ Some non-holders of stocks also report talking to their broker as a source of information in their investment decisions, and opt not to hold such type of investments.

${ }^{26}$ Households respond to: "What sources of information do you (and your family) use to make decisions about saving and investments? (Do you call around, read newspapers, magazines, material you get in the mail, use information from television, radio, the Internet or advertisements? Do you get advice from a friend, relative, lawyer, accountant, banker, broker, or financial planner? Or do you do something else?)"

${ }^{27}$ In a non-reported table, I reproduce Table 2, but restrict my sample to the top $5 \%$ of wealth distribution, and obtain that all results and patterns are robust.
} 
used internet to manage financial investments or to obtain information on investment opportunities. This number drops to $60 \%$ if looking at non-holders of mutual funds. ${ }^{28}$ Finally, their reports show that among owners of mutual funds, internet usage for investment information acquisition reaches as high as $85 \%$.

\subsection{Entry-costs and uncertainty}

Agents are also asked how much risk they are willing to take in a scale from 1 (take substantial financial risk) to 4 (not willing to take any risk). ${ }^{29}$ Participants in the stock market self-report as being less averse to risk. While non-stock holders on average are highly unwilling to take risks, foreign stock holders are less risk averse than domestic stock investors. In 2007, the average response was 3.5 for a non-holder, 2.8 for domestic stock holders and 2.6 for foreign stock holders.

Finally, foreign stocks holders also make positive gains more often with their investments and make losses less often. However, the magnitudes of gains and losses across holders of foreign and domestic stocks give no clear-cut predictions. The 2007 SCF shows that holders of foreign stocks gained more and lost less than holders of domestic stocks only. But this prediction is inverted for some other years of the survey. ${ }^{30}$

The results from the last two subsections bring together the model and the empirical evidence that foreign stock investors are more attentive. It also shows that there is a role for risk aversion and return uncertainty. As a final remark, this section presents some highlights of the two data sets and point to facts that confirm the some of the model predictions. For a complete description of the data sets and a more comprehensive empirical analysis of households portfolio characteristics, I refer the reader to Nechio (2010).

\section{Conclusion}

This paper contributes to the household finance participation puzzle literature in focusing on international holdings of stocks. Participation in foreign stocks markets is very limited and the newest theoretical papers have been pointing to the role of information in determining investments in foreign assets. While the international finance literature has focused on the share of foreign assets held on financial portfolios, this paper looks at the decision to invest in foreign stocks by proposing a model where agents decide on whether to enter the domestic and foreign stock markets. In the model, to update their information set, agents pay a fixed cost out of the their portfolio value. In addition, to account for the costs of acquiring information, a version of the model also features an entry-cost to be paid at the first period by agents that invest in the stock market. This model predicts agents optimally choosing to update their portfolio at equally spaced points in time. More importantly, agents that

\footnotetext{
${ }^{28}$ For more on this survey, see "Ownership of Mutual Funds, Shareholder Sentiment, and Use of the Internet, 2009".

${ }^{29}$ Agents answer to: "Which of the statements on this page comes closest to the amount of financial risk that you and your (husband/wife/partner) are willing to take when you save or make investments? 1. Take substantial financial risks expecting to earn substantial returns; 2. Take above average financial risks expecting to earn above average returns; 3 . Take average financial risks expecting to earn average returns; 4. Not willing to take any financial risks."

${ }^{30}$ To observe gains and losses on stock investments I scale the magnitudes by the amount of financial assets each household owns. To build an aggregate measure of financial assets, I follow the guidelines provided at http://www.federalreserve.gov/PUBS/oss/oss2/bulletin.macro.txt.
} 
invest in foreign stocks update their information set more frequently. After calibrating the model to match returns and volatility for the U.S. economy and different foreign stock investments, I obtain that the minimum entry cost necessary to drive households out of stock markets is quite large, at $78 \%$ of their initial wealth. Such a large number is in line with the findings of the equity premium puzzle literature that points to the high gains of investing in stocks and the elevated risk aversion needed to explain the low participation in such financial investments. Once agents already invest in domestic stock markets, the minimum cost that would drive investors out of foreign stock markets is much smaller and dependent on the model parametrization. The empirical evidence on household portfolios confirms the model predictions by showing that agents that invest in foreign stocks are more attentive and less risk averse. Both empirical and theoretical results point towards the importance of information in determining agents' entry in foreign stock markets.

The calibrated model infers on the size of the entry cost needed to preclude agents from foreign stock investment, and show that the gains from diversification can be substantial. This paper relies on an entry cost to account for the low participation in foreign stock markets. Other possible venues taken by the literature comprise the assumption of borrowing constraints, transaction costs (as in Vissing-Jorgensen (2003)), and background risks, ${ }^{31}$ in addition to participation costs and risk aversion. The results of Section 4 show that indeed, a combination of higher updating costs, risk aversion and uncertainty on asset returns can bring down the minimum cost necessary to drive agents out of the foreign stocks markets. The model also takes aside exchange rate risks by assuming agents can invest in foreign stocks that are traded in U.S. markets. Introducing currency variation risk would bring the minimum entry cost even lower.

Finally, the model does not address life-cycle behavior by leaving aside the effects of age, education, wage income, and background risks. The empirical evidence in the household finance literature shows that such variables are important in determining equity holdings. ${ }^{32}$ However, data evidence reported in Nechio (2010) shows that in fact, the effects of those same variables in foreign holdings of stocks are much smaller. Notwithstanding, extending the model to test for such facts appears to be a challenging and interesting path to pursue in order to contribute to the understanding of the participation in international stock markets.

\footnotetext{
${ }^{31}$ Heaton and Lucas $(2000,2000 b)$ address background risk and its effects on portfolio.

${ }^{32}$ Bertaut and Starr-McCluer (2002) give empirical evidence about the effect of those variables.
} 


\section{References}

[1] Abel, Andrew B., Janice C. Eberly, and Stavros Panageas (2007), "Optimal Inattention to the Stock Market," American Economic Review 97(2): 244-249.

[2] Alvarez, Fernando, Luigi Guiso, and Francesco Lippi (2010), "Durable consumption and asset management with transactions and information costs," Economics Working Papers, ECO2010/04, European University Institute.

[3] Attanasio, Orazio P., and Annette Vissing-Jorgensen (2003), "Stock Market Participation, Intertemporal Substitution and Risk Aversion," American Economic Review, Papers and Proceedings, 93(2): 383-391.

[4] Baumol, William J. (1952), "The Transaction Demand for Cash: An inventory-theoretic approach," Quarterly Journal of Economics 66(4): 545-556.

[5] Bertaut, Carol C., and Martha Starr-McCluer (2002), "Household portfolios in the United States," in Luigi Guiso, Michael Haliassos, and Tullio Jappelli, eds.: Household Portfolios (MIT Press,Cambridge, MA).

[6] Calvet, Laurent, John Y. Campbell, and Paolo Sodini (2007), "Down or out: Assessing the welfare costs of household investment mistakes," Journal of Political Economy 115(5): 707-747.

[7] Curcuru, Stephanie, John Heaton, Deborah Lucas, and Damien Moore (2009), "Heterogeneity and portfolio choice: Theory and evidence," in Yacine Ait-Sahalia and Lars P. Hansen, eds.: Handbook of Financial Econometrics (Elsevier Science, Amsterdam).

[8] Duffie, Darrell, and Tong-sheng Sun. (1990), "Transactions Costs and Portfolio Choice in a DiscreteContinuous-Time Setting,." Journal of Economic Dynamics and Control 14(1): 35-51.

[9] Gabaix, Xavier and D. Laibson (2002), "The 6D Bias and the Equity-Premium Puzzle," in Ben S. Bernanke and Kenneth Rogoff eds., NBER Macroeconomics Annual 16: 257-312.

[10] Guiso, Luigi, Michael Haliassos and Tullio Jappelli, eds.: 2002, Household Portfolios (MIT Press, Cambridge, MA).

[11] Guiso, Luigi, and Tullio Jappelli (2005), "Awareness and stock market participation," Review of Finance 9: 537-567.

[12] Heaton, John, and Deborah Lucas (2000), "Portfolio choice and asset prices: The importance of entrepreneurial risk," Journal of Finance 55(3): 1163-1198.

[13] Heaton, John, and Deborah Lucas (2000b), "Portfolio Choice in the Presence of Background Risk," Economic Journal, Royal Economic Society, 110(460): 1-26.

[14] Huang, Lixin, and Hong Liu (2007), "Rational Inattention and Portfolio Selection.", The Journal of Finance 62(4): 1999-2040. 
[15] Investment Company of America (2009), "2009 Investment Company Fact Book - A Review of Trends and Activity in the Investment Company Industry," Washington, D. C.: Investment Company Institute, available at: http://www.ici.org/pdf/2009_factbook.pdf

[16] Investment Company of America (2009), "Ownership of Mutual Funds, Shareholder Sentiment, and Use of the Internet, 2009," Washington, D. C.: Investment Company Institute, available at: http://www.ici.org/pdf/fm-v18n7.pdf.

[17] Investment Company of America and the Securities Industry Association (2008),"Equity and bond ownership in America," Washington, D. C.: Investment Company Institute, available at: http://www.ici.org/pdf/rpt_08_equity_owners.pdf.

[18] Investment Company of America and the Securities Industry Association (2005),"Equity ownership in America," Washington, D. C.: Investment Company Institute, available at: http://www.ici.org/pdf/rpt_05_equity_owners.pdf.

[19] Jones, Charles (2002), "A Century of Stock Market Liquidity and Trading Costs," working paper available at http://papers.ssrn.com/sol3/papers.cfm?abstract_id=313681.

[20] Lewis, Karen K. (1999), "Trying to Explain Home Bias in Equities and Consumption," Journal of Economic Literature 37(2): 571-608.

[21] Merton, Robert C. (1969), "Lifetime Portfolio Selection under Uncertainty: The Continuous-Time Case," The Review of Economics and Statistics 51(3): 247-257.

[22] Merton, Robert C. (1971), "Optimum consumption and portfolio rules in a continuous-time model," Journal of Economic Theory 3: 373-413.

[23] Merton, Robert C. (1973), "An intertemporal capital asset pricing model," Econometrica 41: 867887.

[24] Miller, Merton and D. Orr (1966), "A Model of the Demand for Money by Firms", Quarterly Journal of Economics 80(3): 413-442.

[25] Mondria, Jordi and T. Wu (2010), "The Puzzling Evolution of the Home Bias, Information Processing and Financial Openness," Journal of Economic Dynamics \& Control 34: 875-896.

[26] Nechio, F. (2010b), "Foreign stock holdings and the role of information - an empirical approach," mimeo.

[27] Polkovnichenko, Valery (2005), "Household portfolio diversification: A case for rank dependent preferences," Review of Financial Studies 18: 1467-1502.

[28] Samuelson, Paul A. (1969), "Lifetime Portfolio Selection by Dynamic Stochastic Programming," Review of Economics and Statistics 51(3): 239-46.

[29] Veldkamp, Laura and Stijn Van Nieuwerburgh (2010), "Information Acquisition and UnderDiversification, with Information Acquisition and Under-Diversification," Review of Economic Studies, forthcoming. 
[30] Vissing-Jorgensen, Annette (2003), "Perspectives on behavioral finance: Does "irrationality" disappear with wealth? Evidence from expectations and actions," in Mark Gertler and Kenneth Rogoff, eds.: NBER Macroeconomics Annual (MIT Press, Cambridge, MA).

[31] Weisbenner, Scott (2002), "Do pension plans with participant investment choice teach households to hold more equity?," Journal of Pension Economics and Finance 1: 223-248 Cambridge University Press 


\section{A Technical appendix to "Foreign stock holdings: the role of infor- mation"}

\section{A.1 The Model}

In this Section, I depart from Abel, Eberly and Panageas (2007) in two directions; I first introduce foreign stocks on agents portfolio and then, in line with my previous results, I discuss the role of an entry cost in such market.

Consumer's wealth is held on an investment portfolio and in a riskless liquid asset for transactions. If she decides on entering the stock market, the investment portfolio is composed of a riskless bond and risky stocks, domestic and foreign. The consumer pays a fixed cost to observe their portfolio, proportional to the portfolio' contemporaneous value. Hence, it's optimal for the consumer to check her investment at equally spaced points in time, consuming from a riskless transactions account in the interim. A manager continuously rebalances the portfolio, at each period to guarantee a constant share is held in each type of asset within observation periods.

The consumer maximizes:

$$
\begin{aligned}
& E_{t} \int_{0}^{\infty} \frac{1}{1-\alpha} c_{t+s}^{1-\alpha} e^{-\rho s} d s, \\
0< & \alpha \neq 1 \\
\rho> & 0
\end{aligned}
$$

where $c$ stands for consumption, $0<\alpha \neq 1$ is the inverse of the intertemporal elasticity of substitution and $\rho>0$ is the intertemporal rate of discount.

The investment portfolio is composed of a riskless bond that pays rate of return $r>0$, and of non-dividend-paying domestic and foreign stocks with prices $D_{t}$ and $F_{t}$, respectively, with $P_{t}=\left(\begin{array}{c}D_{t} \\ F_{t}\end{array}\right)$ following a geometric Brownian motion:

$$
\begin{aligned}
\frac{d P_{t}}{P_{t}} & =\mu d t+\sqrt{\Omega} d Z \\
\mu & >R
\end{aligned}
$$

where:

$$
\begin{aligned}
& \mu=\left(\begin{array}{l}
\mu_{d} \\
\mu_{f}
\end{array}\right), R=\left(\begin{array}{l}
r \\
r
\end{array}\right) \\
& \Omega=\left(\begin{array}{ll}
\sigma_{d}^{2} & \sigma_{d f} \\
\sigma_{d f} & \sigma_{f}^{2}
\end{array}\right),
\end{aligned}
$$

and $\mathrm{Z}$ is a Wiener process, $\mu_{d}$ and $\mu_{f}$ are the returns on domestic and foreign stocks, respectively, and $\Omega$ is the variance-covariance matrix of stocks returns.

The consumer can observe the investment portfolio by paying a fraction $\theta, 0 \leq \theta<1$, of the contemporaneous value of the investment portfolio. She can only withdraw funds from the portfolio if she observes the value. She also holds a riskless liquid asset that pays $r^{L}$, with $0 \leq r^{L}<r$, to finance 
consumption.

Let $t_{j}, j=1,2,3, \ldots$, be the times at which consumer observes the value of her portfolio. At time $t_{j}$, she chooses: the next "observation" date, $t_{j+1}=t+\tau$; the amount of the riskless liquid asset, $X_{t_{j}}(\tau)$ to finance consumption from $t_{j}$ to $t_{j+1}$; and the fraction $\phi$ invested in domestic $\left(\phi_{d}\right)$ and foreign $\left(\phi_{f}\right)$ stocks:

$$
\phi=\left(\begin{array}{c}
\phi_{d} \\
\phi_{f}
\end{array}\right)
$$

From time $t_{j}$ to $t_{j+1}$, the amount of riskless asset to finance consumption is:

$$
\phi=\left(\begin{array}{l}
\phi_{d} \\
\phi_{f}
\end{array}\right)
$$

From time $t_{j}$ to $t_{j+1}$, the amount of riskless asset to finance consumption is:

$$
X_{t_{j}}(\tau)=\int_{0}^{\tau} c_{t_{j+s}} e^{-r^{L} s} d s
$$

and since $r^{L}<r$, when "observation" time arrives, the value in the riskless asset will have reached zero, i.e., $X_{t_{\tau}}=0$. At this time, the consumer pays the observation cost and the value of her wealth after paying such cost is:

$$
W_{t_{j+\tau}}=(1-\theta)^{\prime}\left(W_{t_{j}}-X_{t_{j}}\right) \mathcal{R}\left(t_{j}, t_{j}+\tau\right),
$$

where $\mathcal{R}\left(t_{j}, t_{j}+\tau\right)$ is the gross rate of return to investment from time $t_{j}$ and $t_{j+\tau}$, and $\mathcal{R}\left(t_{j}, t_{j+\tau}\right)=1$.

Following the Abel et. al. (2007), for simplicity, I also assume that a portfolio manager continuously rebalances the portfolio to maintain fixed the proportion of assets invested in stocks. In this case, the portfolio return then follows a geometric Brownian motion;

$$
\frac{d \mathcal{R}\left(t_{j}, t_{j}+s\right)}{\mathcal{R}\left(t_{j}, t_{j}+s\right)}=\left[r+\phi^{\prime}(\mu-R)\right] d s+\phi^{\prime} \sqrt{\Omega} d Z
$$

To solve the consumer's problem, I divide the problem in four steps: the consumption choice within two consecutive observation periods; the choice of riskless asset and the share invested in stocks; and two final steps that uncover the value function and the optimal observational frequency.

1. Choosing consumption between $t_{j}$ and $t_{j}+\tau$, given $\tau$ and $X_{t_{j}}$

$$
\begin{aligned}
U_{t_{j}}(\tau) & \equiv \operatorname{Max} \int_{0}^{\tau} \frac{1}{1-\alpha} c_{t_{j}+s}^{1-\alpha} e^{-\rho s} d s \\
s t & : \quad \int_{0}^{\tau} c_{t_{j}+s} e^{-r^{L} s} d s \\
X_{t_{j}}(\tau)= & \\
F O C & : \quad d X_{t_{j}} \\
c_{t_{j}}^{-\alpha} & =\eta \\
c_{t_{j}+s}^{-\alpha} e^{-\rho s} & =\eta e^{-r^{L s}}
\end{aligned}
$$


This implies:

$$
c_{t_{j}+s}=c_{t_{j}} e^{\frac{-\left(\rho-r^{L}\right) s}{\alpha}}, \text { for } 0 \leq s<\tau
$$

Substituting (13) into (12):

$$
\begin{aligned}
X_{t_{j}} & =\int_{0}^{\tau} c_{t_{j}} e^{\frac{-\left(\rho-r^{L}\right) s}{\alpha}} e^{-r^{L} s} d s \\
& =c_{t_{j}} h(\tau)
\end{aligned}
$$

where:

$$
\begin{aligned}
h(\tau) & =\int_{0}^{\tau} e^{-\omega s} d s=\frac{1-e^{-\omega \tau}}{\omega} \\
\omega & =\frac{\left(\rho-(1-\alpha) r^{L}\right)}{\alpha}
\end{aligned}
$$

Assume $\omega>0$.

Substitute (13) into (11) and using (14):

$$
\begin{aligned}
U_{t_{j}}(\tau) & \equiv \operatorname{Max} \int_{0}^{\tau} \frac{1}{1-\alpha}\left[c_{t_{j}+s}^{1-\alpha}\right] e^{-\rho s} d s \\
& =\frac{1}{1-\alpha} \int_{0}^{\tau}\left[c_{t_{j}} e^{\frac{-\left(\rho-r^{L}\right) s}{\alpha}}\right]^{1-\alpha} e^{-\rho s} d s \\
& =\frac{1}{1-\alpha} c_{t_{j}}^{1-\alpha} \int_{0}^{\tau}\left[e^{\frac{-\left(\rho-r^{L}\right) s}{\alpha}}\right]^{1-\alpha} e^{-\rho s} d s \\
& =\frac{1}{1-\alpha} c_{t_{j}}^{1-\alpha} \int_{0}^{\tau} e^{\frac{-\left(\rho-(1-\alpha) r^{L}\right)}{\alpha} s} d s \\
& =\frac{1}{1-\alpha}\left(\frac{X_{t_{j}}}{h(\tau)}\right)^{1-\alpha} h(\tau) \\
& =\frac{1}{1-\alpha} X_{t_{j}}^{1-\alpha} h(\tau)^{\alpha}
\end{aligned}
$$

2. Choosing $X_{t_{j}}$ and $\phi$, given $\tau$

Given $\tau$, the consumer problem is the same as in classic Samuelson (1969); at times when the consumer observes the portfolio, the value function equals:

$$
V\left(W_{t_{j}}\right)=\max _{X_{t_{j}}, \phi} U_{t_{j}}(\tau)+e^{-\rho \tau} E\left\{V\left[(1-\theta)\left(W_{t_{j}}-X_{t_{j}}\right) R\left(t_{j}, t_{j}+\tau\right)\right]\right\}
$$

Guess that:

$$
V\left(W_{t_{j}}\right)=\frac{1}{1-\alpha} \gamma W_{t_{j}}^{1-\alpha}
$$

where $\gamma$ is to be determined. 
Replacing (16) and (18) into (17):

$$
\begin{aligned}
\frac{1}{1-\alpha} \gamma W_{t_{j}}^{1-\alpha}= & \max _{X_{t_{j}}, \phi} \frac{1}{1-\alpha} X_{t_{j}}^{1-\alpha} h(\tau)^{\alpha}+e^{-\rho \tau} E_{t_{j}}\left\{\frac{1}{1-\alpha} \gamma\left[(1-\theta)\left(W_{t_{j}}-X_{t_{j}}\right) R\left(t_{j}, t_{j}+\tau\right)\right]^{1-\alpha}\right\} \\
= & \max _{X_{t_{j}}, \phi} \frac{1}{1-\alpha} X_{t_{j}}^{1-\alpha} h(\tau)^{\alpha} \\
& +e^{-\rho \tau} \frac{1}{1-\alpha} \gamma(1-\theta)^{1-\alpha}\left(W_{t_{j}}-X_{t_{j}}\right)^{1-\alpha} E_{t_{j}}\left\{\left[R\left(t_{j}, t_{j}+\tau\right)\right]^{1-\alpha}\right\}
\end{aligned}
$$

The optimal allocation of the investment portfolio maximizes:

$$
\begin{aligned}
& \frac{1}{1-\alpha} E\left\{\left[R\left(t_{j}, t_{j}+\tau\right)\right]^{1-\alpha}\right\} \\
= & \frac{1}{1-\alpha} \exp \left\{(1-\alpha)\left(r+\phi^{\prime}(\mu-R)-\frac{1}{2} \alpha \phi^{\prime} \Omega \phi\right) \tau\right\}
\end{aligned}
$$

Replacing the last equation in the maximization problem (19), the first order constraint with respect to $\phi$ is:

$$
\begin{aligned}
0=\gamma(1-\theta)^{1-\alpha}\left(W_{t_{j}}-X_{t_{j}}\right)^{1-\alpha} \frac{1}{1-\alpha} \exp \left\{(1-\alpha)\left(r+\phi^{\prime}(\mu-R)-\frac{1}{2} \alpha \phi^{\prime} \Omega \phi\right) \tau\right\} * \\
(1-\alpha) \tau\left[(\mu-R)-\alpha \phi^{\prime} \Omega\right] \\
\phi^{*}=\frac{1}{\alpha} \Omega^{-1}(\mu-R) \\
\phi^{*^{\prime}}=\frac{1}{\alpha}(\mu-R)^{\prime} \Omega^{-1}
\end{aligned}
$$

Substituting (21) into (20):

$$
\begin{aligned}
& \max _{\phi} \frac{1}{1-\alpha} \exp (-\rho \tau) E_{t_{j}}\left\{\left[R\left(t_{j}, t_{j}+\tau\right)\right]^{1-\alpha}\right\} \\
= & \frac{1}{1-\alpha} \exp (-\rho \tau) \exp \left\{(1-\alpha)\left(r+\phi^{\prime}(\mu-R)-\frac{1}{2} \alpha \phi^{\prime} \Omega \phi\right) \tau\right\} \\
= & \frac{1}{1-\alpha} \exp \left\{-\rho \tau+(1-\alpha)\left(\begin{array}{c}
r+\frac{1}{\alpha}(\mu-R)^{\prime} \Omega^{-1}(\mu-R) \\
-\frac{1}{2} \alpha \frac{1}{\alpha}(\mu-R)^{\prime} \Omega^{-1} \Omega \frac{1}{\alpha} \Omega^{-1}(\mu-R)
\end{array}\right) \tau\right\} \\
= & \frac{1}{1-\alpha} \exp \left\{-\rho \tau+(1-\alpha)\left(r+\frac{1}{2} \frac{1}{\alpha}(\mu-R)^{\prime} \Omega^{-1}(\mu-R)\right) \tau\right\} \\
= & \frac{1}{1-\alpha} \exp \left\{-\tau\left[\rho-(1-\alpha)\left(r+\frac{1}{2} \frac{1}{\alpha}(\mu-R)^{\prime} \Omega^{-1}(\mu-R)\right)\right]\right\}
\end{aligned}
$$

Call:

$$
\begin{aligned}
\Omega(\alpha) & \equiv\left(r+\frac{1}{2} \frac{1}{\alpha}(\mu-R)^{\prime} \Omega^{-1}(\mu-R)\right)>r^{L} \\
\lambda & =\frac{\rho-(1-\alpha) \Omega(\alpha)}{\alpha}>0
\end{aligned}
$$


Then, we can rewrite:

$$
\begin{aligned}
& \max _{\phi} \frac{1}{1-\alpha} \exp (-\rho \tau) E_{t_{j}}\left\{\left[R\left(t_{j}, t_{j}+\tau\right)\right]^{1-\alpha}\right\} \\
= & \frac{1}{1-\alpha} \exp \left\{-\tau\left[\rho-(1-\alpha)\left(r+\frac{1}{2} \frac{1}{\alpha}(\mu-R)^{\prime} \Omega^{-1}(\mu-R)\right)\right]\right\} \\
= & \frac{1}{1-\alpha} \exp \{-\alpha \lambda \tau\}
\end{aligned}
$$

Substitute this last equation into (19):

$$
\begin{aligned}
\frac{1}{1-\alpha} \gamma W_{t_{j}}^{1-\alpha}= & \max _{X_{t_{j}}, \phi} \frac{1}{1-\alpha} X_{t_{j}}^{1-\alpha} h(\tau)^{\alpha} \\
& +e^{-\rho \tau} \frac{1}{1-\alpha} \gamma(1-\theta)^{1-\alpha}\left(W_{t_{j}}-X_{t_{j}}\right)^{1-\alpha} E_{t_{j}}\left\{\left[R\left(t_{j}, t_{j}+\tau\right)\right]^{1-\alpha}\right\} \\
= & \max _{X_{t_{j}}, \phi} \frac{1}{1-\alpha} X_{t_{j}}^{1-\alpha}[h(\tau)]^{\alpha} \\
& +\frac{1}{1-\alpha} \gamma(1-\theta)^{\frac{\alpha(1-\alpha)}{\alpha}}\left(W_{t_{j}}-X_{t_{j}}\right)^{1-\alpha} \exp \{-\alpha \lambda \tau\} \\
= & \max _{X_{t_{j}}, \phi} \frac{1}{1-\alpha} X_{t_{j}}^{1-\alpha}[h(\tau)]^{\alpha}+\frac{1}{1-\alpha} \gamma\left(W_{t_{j}}-X_{t_{j}}\right)^{1-\alpha} \chi^{\alpha} e^{-\alpha \lambda \tau}
\end{aligned}
$$

where $\chi=(1-\theta)^{\frac{(1-\alpha)}{\alpha}}$.

Differentiate the RHS of the above equation with respect to $X_{t_{j}}$ and set the derivative equal to zero to obtain:

$$
\begin{aligned}
X_{t_{j}}^{-\alpha}[h(\tau)]^{\alpha} & =\gamma\left(W_{t_{j}}-X_{t_{j}}\right)^{-\alpha} \chi^{\alpha} e^{-\alpha \lambda \tau} \\
X_{t_{j}} & =h(\tau) \gamma^{-\frac{1}{\alpha}}\left(W_{t_{j}}-X_{t_{j}}\right) \chi^{-1} e^{\lambda \tau}
\end{aligned}
$$

Define

$$
A=h(\tau) \gamma^{-\frac{1}{\alpha}} \chi^{-1} e^{\lambda \tau}
$$

Then,

$$
\begin{aligned}
X_{t_{j}} & =A\left(W_{t_{j}}-X_{t_{j}}\right) \\
(1+A) X_{t_{j}} & =A W_{t_{j}} \\
X_{t_{j}} & =\frac{A}{(1+A)} W_{t_{j}}
\end{aligned}
$$

3. Given $X_{t_{j}}$ and $\phi$ conditional on $\tau$, the consumer computes the value function on $\tau$ 
Replace $X_{t_{j}}$ into the value function $(22)$, (or $\left.(3)\right)$ to obtain $\gamma(\tau)$ :

$$
\begin{aligned}
\frac{1}{1-\alpha} \gamma W_{t_{j}}^{1-\alpha} & =\max _{X_{t_{j}}, \phi} \frac{1}{1-\alpha} X_{t_{j}}^{1-\alpha}[h(\tau)]^{\alpha}+\frac{1}{1-\alpha} \gamma\left(W_{t_{j}}-X_{t_{j}}\right)^{1-\alpha} \chi^{\alpha} e^{-\alpha \lambda \tau} \\
\frac{1}{1-\alpha} \gamma\left[\frac{1+A}{A} X_{t_{j}}\right]^{1-\alpha} & =\frac{1}{1-\alpha} X_{t_{j}}^{1-\alpha}[h(\tau)]^{\alpha}+\frac{1}{1-\alpha} \gamma\left(\frac{X_{t_{j}}}{A}\right)^{1-\alpha} \chi^{\alpha} e^{-\alpha \lambda \tau} \\
\frac{1}{1-\alpha} \gamma\left(\frac{1+A}{A}\right)^{1-\alpha} & =\frac{1}{1-\alpha}[h(\tau)]^{\alpha}+\frac{1}{1-\alpha} \gamma\left(\frac{1}{A}\right)^{1-\alpha} \chi^{\alpha} e^{-\alpha \lambda \tau} \\
\gamma(\tau) & =\left(\frac{A}{1+A}\right)^{1-\alpha}[h(\tau)]^{\alpha}+\gamma(\tau)\left(\frac{1}{1+A}\right)^{1-\alpha} \chi^{\alpha} e^{-\alpha \lambda \tau}
\end{aligned}
$$

Equations (23) and (24) are two equations on $\gamma(\tau)$ and $A$. Using the definition of $h(\tau)$ in $(15)$ and solving this system:

$$
\begin{aligned}
A & =\chi^{-1} e^{\lambda \tau}-1 \\
\gamma(\tau) & =\left[\frac{1-e^{-\omega \tau}}{1-\chi e^{-\lambda \tau}}\right]^{\alpha} \omega^{-\alpha}
\end{aligned}
$$

4. The consumer maximizes the value function and sets $\tau$.

To choose $\tau$, the consumer maximizes (18), that is equivalent to maximizing:

$$
\begin{gathered}
F(\tau)=\frac{\gamma(\tau)}{1-\alpha} \\
\operatorname{Max}_{\tau} \frac{\gamma(\tau)}{1-\alpha}=\frac{\left[\frac{1-e^{-\omega \tau}}{1-\chi e^{-\lambda \tau}}\right]^{\alpha} \omega^{-\alpha}}{1-\alpha} \\
\Rightarrow \quad \frac{\left[\frac{1-e^{-\omega \tau}}{1-\chi e^{-\lambda \tau}}\right]^{\alpha-1} \omega^{-\alpha}}{1-\alpha}\left(\frac{\left(\omega e^{-\omega \tau}\right)\left(1-\chi e^{-\lambda \tau}\right)-\left(\chi \lambda e^{-\lambda \tau}\right)\left(1-e^{-\omega \tau}\right)}{\left(1-\chi e^{-\lambda \tau}\right)^{2}}\right)=0 \\
\frac{\partial F(\tau)}{\partial \tau}=\frac{\left(1-\chi e^{-\lambda \tau}\right)-\left(\chi \lambda e^{-\lambda \tau}\right)\left(1-e^{-\omega \tau}\right)=0}{\left(\omega e^{-\omega \tau}\right)}=0 \\
\omega e^{-\omega \tau}-\omega \chi e^{-(\omega+\lambda) \tau}-\chi \lambda e^{-\lambda \tau}+\chi \lambda e^{-(\omega+\lambda) \tau}=0 \\
(-\omega \chi+\chi \lambda) e^{-(\omega+\lambda) \tau}=-\omega e^{-\omega \tau}+\chi \lambda e^{-\lambda \tau} \\
(-\omega \chi+\chi \lambda) e^{-(\omega+\lambda) \tau}=-\omega e^{-\omega \tau}+\chi \lambda e^{-\lambda \tau}
\end{gathered}
$$

Divide by $\omega \chi e^{-\omega \tau}$ :

$$
\begin{aligned}
\frac{(-\omega+\lambda)}{\omega} e^{-\lambda \tau} & =-\frac{1}{\chi}+\frac{\lambda}{\omega} e^{(\omega-\lambda) \tau} \\
\frac{(\omega-\lambda)}{\omega} e^{-\lambda \tau}+\frac{\lambda}{\omega} e^{(\omega-\lambda) \tau} & =\frac{1}{\chi}
\end{aligned}
$$


As in Abel et al. (2007), define:

$$
M(\tau) \equiv \frac{(\omega-\lambda)}{\omega} e^{-\lambda \tau}+\frac{\lambda}{\omega} e^{(\omega-\lambda) \tau}
$$

In Abel et al. (2007), it is proven that $\tau^{*}$ that maximizes $F(\tau)$ is such that $M\left(\tau^{*}\right) \chi=1$, i.e.. ${ }^{33}$

$$
\frac{(\omega-\lambda)}{\omega} e^{-\lambda \tau^{*}}+\frac{\lambda}{\omega} e^{(\omega-\lambda) \tau^{*}}-\frac{1}{\chi}=0
$$

A second order Taylor expansion to $M(\tau)$ around $\tau=0$ yields:

$$
\begin{aligned}
M(\tau) & \equiv \frac{(\omega-\lambda)}{\omega}+\frac{\lambda}{\omega}=1 \\
M^{\prime}(\tau) & =\frac{-\lambda(\omega-\lambda)}{\omega} e^{-\lambda \tau}+\frac{\lambda(\omega-\lambda)}{\omega} e^{(\omega-\lambda) \tau} \\
M^{\prime \prime}(\tau) & =\left(\lambda^{2}\right) \frac{(\omega-\lambda)}{\omega} e^{-\lambda \tau}+\frac{\lambda(\omega-\lambda)^{2}}{\omega} e^{(\omega-\lambda) \tau} \\
M(0) & =\frac{(\omega-\lambda)}{\omega} e^{-\lambda \tau}+\frac{\lambda}{\omega} e^{(\omega-\lambda) \tau} \\
M^{\prime}(0) & =\frac{-\lambda(\omega-\lambda)}{\omega}+\frac{\lambda(\omega-\lambda)}{\omega}=0 \\
M^{\prime \prime}(0) & =\left(\lambda^{2}\right) \frac{(\omega-\lambda)}{\omega}+\frac{\lambda(\omega-\lambda)^{2}}{\omega} \\
& =\lambda(\omega-\lambda) \neq 0
\end{aligned}
$$

For any $f(x)$, a second order Taylor expansion gives:

$$
f(x) \simeq f(a)+(x-a) f^{\prime}(a)+\frac{1}{2}(x-a)^{2} f^{\prime \prime}(a)
$$

For $M(\tau)$, we get:

$$
M(\tau) \simeq 1+\tau * 0+\frac{1}{2}(\tau)^{2} \lambda(\omega-\lambda)
$$

Let $\hat{\tau}$ be the approximately optimal value of $\tau$. From Abel et al. $(2007)$ it satisfies $M(\hat{\tau}) \chi=1$, and that implies:

$$
\begin{aligned}
\frac{1}{2}(\hat{\tau})^{2} & =\frac{\chi^{-1}-1}{\lambda(\omega-\lambda)} \\
\hat{\tau} & =\left(\frac{2\left(\chi^{-1}-1\right)}{(\omega-\lambda) \lambda}\right)^{\frac{1}{2}}
\end{aligned}
$$

\footnotetext{
${ }^{33}$ For a proof that $\tau^{*}$ is a unique maximum of this function, I refer the reader to Lemma 1 of Abel et al. (2007).
} 


\section{A.2 The entry decision}

Agents can opt not to enter the stock market. If the consumer decides to never enter this market and hold all its wealth in the riskless liquid asset, her overall rate of return equals $r^{L}$. From the definitions of $\lambda$ and $\omega$, the non-entry decision implies $\lambda=\omega$, and so, $\gamma=\omega^{-\alpha}$.

Hence, for such an agent, her value function equals:

$$
V\left(W_{0}\right)=\omega^{-\alpha} \frac{W_{0}^{1-\alpha}}{1-\alpha}=g
$$

I assume agents have to pay a fixed cost, $K$, out of initial wealth, $W_{0}$, at time 0 , when entering the stock market. Let's first assume the agent enters the domestic market only and for that, he pays $K_{d}$.

If he enters the stock market, she pays $K_{d}$ and her value function is:

$$
\begin{gathered}
V\left(W_{0}^{+}\right)=V\left(W_{0}\left(1-K_{d}\right)\right)=\gamma(\tau) \frac{\left(W_{0}\left(1-K_{d}\right)\right)^{1-\alpha}}{1-\alpha} \\
\gamma(\tau)=\left[\frac{1-e^{-\omega \tau}}{1-\left[(1-\theta)^{\frac{(1-\alpha)}{\alpha}}\right] e^{-\lambda \tau}}\right]^{\alpha} \omega^{-\alpha} \\
\tau=\left(\frac{2\left((1-\theta)^{-\frac{(1-\alpha)}{\alpha}}-1\right)}{(\omega-\lambda) \lambda}\right)^{\frac{1}{2}}
\end{gathered}
$$

where:

$$
\begin{gathered}
\omega=\frac{\left(\rho-(1-\alpha) r^{L}\right)}{\alpha} \\
\Omega(\alpha) \equiv\left(r+\frac{1}{2} \frac{1}{\alpha}(\mu-R)^{\prime} \Omega^{-1}(\mu-R)\right)>r^{L} \\
\lambda=\frac{\rho-(1-\alpha) \Omega(\alpha)}{\alpha}>0
\end{gathered}
$$

1. How large $K_{d}$ has to be to drive agents out of the domestic market, if this is the only available risky asset, as in Abel et al. (2007)?

I identify the parameters of their model by a subscript $d$ to distinguish from the parameters of the open economy model. For this case, $K_{d}$ has to be such that equals the value function of consumers that invest and those who don't invest in stocks, that is, comparing (3) to (7):

$$
\begin{gathered}
V\left(W_{0}^{+}\right)=V\left(W_{0}\left(1-K_{d}\right)\right)=\gamma_{d}(\tau) \frac{\left(W_{0}\left(1-K_{d}\right)\right)^{1-\alpha}}{1-\alpha}=g=\omega^{-\alpha} \frac{W_{0}^{1-\alpha}}{1-\alpha} \\
\gamma_{d}(\tau) \frac{\left(W_{0}\left(1-K_{d}\right)\right)^{1-\alpha}}{1-\alpha}=\omega^{-\alpha} \frac{W_{0}^{1-\alpha}}{1-\alpha}
\end{gathered}
$$




$$
\begin{aligned}
1 & =\left[\frac{1-e^{-\omega \tau_{d}}}{1-\left[(1-\theta)^{\frac{(1-\alpha)}{\alpha}}\right] e^{-\lambda_{d} \tau_{d}}}\right]^{\alpha}\left(1-K_{d}\right)^{1-\alpha} \\
K_{d} & =1-\left[\frac{1-e^{-\omega \tau_{d}}}{1-\left[(1-\theta)^{\frac{(1-\alpha)}{\alpha}}\right] e^{-\lambda_{d} \tau_{d}}}\right]^{-\frac{\alpha}{1-\alpha}} \\
K_{d} & =1-\left(\frac{1-e^{-\omega \tau_{d}}}{1-\left[(1-\theta)^{\frac{(1-\alpha)}{\alpha}}\right] e^{-\lambda_{d} \tau_{d}}}\right)^{\frac{-\alpha}{1-\alpha}}
\end{aligned}
$$

where

$$
\begin{aligned}
\phi_{d} & =\frac{1}{\alpha} \frac{\left(\mu_{d}-r\right)}{\sigma^{2}} \\
\Omega_{d}(\alpha) & \equiv\left(r+\frac{1}{2} \frac{1}{\alpha} \frac{\left(\mu_{d}-r\right)^{2}}{\sigma_{d}^{2}}\right)>r^{L} \\
\lambda_{d} & =\frac{\rho-(1-\alpha) \Omega_{d}(\alpha)}{\alpha} .
\end{aligned}
$$

2. How large $K_{f}$ has to be to drive agents out of foreign market given they invest in domestic stocks?

When agents enter only the domestic market, the problem is the same as presented in Abel et. al. (2007), and hence, the two equations to be compared are given by:

$$
\begin{gathered}
{\left[\frac{1-e^{-\omega \tau}}{1-\left[(1-\theta)^{\frac{(1-\alpha)}{\alpha}}\right] e^{-\lambda \tau}}\right]^{\alpha} \omega^{-\alpha} \frac{\left(W_{0}\left(1-K_{f}\right)\right)^{1-\alpha}}{1-\alpha}=\left[\frac{1-e^{-\omega \tau_{d}}}{1-\left[\left(1-\theta_{d}\right)^{\frac{(1-\alpha)}{\alpha}}\right] e^{-\lambda_{d} \tau_{d}}}\right]^{\alpha} \omega^{-\alpha} \frac{W_{0}^{1-\alpha}}{1-\alpha},} \\
K_{f}=1-\left(\frac{\frac{1-\left[\left(1-\theta_{d}\right)^{\frac{(1-\alpha)}{\alpha}}\right] e^{-\lambda_{d} \tau}}{1-\left[(1-\theta)^{\frac{(1-\alpha)}{\alpha}}\right] e^{-\lambda \tau}}}{\frac{1-e^{-\omega \tau}}{1-\alpha}}\right)
\end{gathered}
$$

\section{A.3 Proofs of Propositions}

Proposition 1 The solution to the consumer's problem implies that:

a. The value function is such that:

$$
V(W)=\gamma(\tau) \frac{W^{1-\alpha}}{1-\alpha}
$$

where:

$$
\gamma(\tau)=\left[\frac{1-e^{-\omega \tau}}{1-\chi e^{-\lambda \tau}}\right]^{\alpha} \omega^{-\alpha}
$$


b. The optimal shares held in domestic and foreign stocks equal:

$$
\phi^{*}=\frac{1}{\alpha} \Omega^{-1}(\mu-R)
$$

c. And the consumer optimally chooses to observe and update her portfolio at time $\tau^{*}$, obtained from solving:

$$
\frac{(\omega-\lambda)}{\omega} e^{-\lambda \tau^{*}}+\frac{\lambda}{\omega} e^{(\omega-\lambda) \tau^{*}}-\frac{1}{\chi}=0
$$

A second order approximation to this equation yields:

$$
\hat{\tau}^{*}=\left(\frac{2\left(\chi^{-1}-1\right)}{(\omega-\lambda) \lambda}\right)^{\frac{1}{2}}
$$

where $\chi=(1-\theta)^{\frac{(1-\alpha)}{\alpha}}, \omega=\frac{\left(\rho-(1-\alpha) r^{L}\right)}{\alpha}$ and $\lambda=\frac{\rho-(1-\alpha)\left(r+\frac{1}{2} \frac{1}{\alpha}(\mu-R)^{\prime} \Omega^{-1}(\mu-R)\right)}{\alpha}$.

Proof. Following steps 1-4 of the detailed model derivation described in Subsection A.1 provides the proof for the proposition and extensively describe how to obtain the above equations.

Proposition 2 As long as $0<\mu-R<1$, the total share invested in stocks is positive, even though the share invested in one or the other can be negative.

$$
\phi_{d}+\phi_{f}>0
$$

\section{Proof.}

$$
\begin{aligned}
& \left(\mu_{d}-r\right) \sigma_{f}^{2}-\left(\mu_{d}-r\right) \sigma_{d f}+\left(\mu_{f}-r\right) \sigma_{d}^{2}-\left(\mu_{f}-r\right) \sigma_{d f} \\
> & \left(\mu_{d}-r\right) \sigma_{f}^{2}-\left(\mu_{d}-r\right) \sigma_{d} \sigma_{f}+\left(\mu_{f}-r\right) \sigma_{d}^{2}-\left(\mu_{f}-r\right) \sigma_{d} \sigma_{f} \\
> & \left(\mu_{d}-r\right)\left(\sigma_{f}^{2}-\sigma_{d} \sigma_{f}\right)+\left(\mu_{f}-r\right)\left(\sigma_{d}^{2}-\sigma_{d} \sigma_{f}\right) \\
> & \left(\mu_{d}-r\right) \sigma_{f}\left(\sigma_{f}-\sigma_{d}\right)+\left(\mu_{f}-r\right) \sigma_{d}\left(\sigma_{d}-\sigma_{f}\right) \\
= & \left(\sigma_{f}-\sigma_{d}\right)\left[\left(\mu_{d}-r\right) \sigma_{f}-\left(\mu_{f}-r\right) \sigma_{d}\right] \\
> & \left(\sigma_{f}-\sigma_{d}\right)\left[\left(\mu_{d}-r\right) \sigma_{f}-\sigma_{d}\right]
\end{aligned}
$$

And $0<\left(\mu_{d}-r\right)<1$. If $\left(\left(\mu_{d}-r\right) \sigma_{f}-\sigma_{d}\right)>0 \Rightarrow\left(\sigma_{f}-\sigma_{d}\right)>0$. If $\left(\left(\mu_{d}-r\right) \sigma_{f}-\sigma_{d}\right)<0 \Rightarrow \sigma_{f}<$ $\frac{\sigma_{d}}{\left(\mu_{d}-r\right)}<\sigma_{d}$. And hence, the above expression is positive.

Proposition 3 Regardless the availability of foreign stocks, the following assessments are still true that:

$$
\frac{\partial \tau^{*}}{\partial \theta}>0, \frac{\partial \tau^{*}}{\partial r^{L}}>0
$$


Proof. Following Abel et al. (2007):

$$
\begin{aligned}
M(\tau) & \equiv \frac{(\omega-\lambda)}{\omega} e^{-\lambda \tau}+\frac{\lambda}{\omega} e^{(\omega-\lambda) \tau} \\
M\left(\tau^{*}\right) \chi & =1 \\
\chi & =(1-\theta)^{\frac{(1-\alpha)}{\alpha}} \\
\omega & =\frac{\left(\rho-(1-\alpha) r^{L}\right)}{\alpha}
\end{aligned}
$$

Total differentiating the above equation:

$$
\begin{gathered}
\frac{d M}{d \tau^{*}} \frac{d \tau^{*}}{d \theta} \chi+\frac{d \chi}{d \theta} M\left(\tau^{*}\right)=0 \\
\frac{d \chi}{d \theta}=-\frac{(1-\alpha)}{\alpha}(1-\theta)^{\frac{(1-\alpha)}{\alpha}-1} \\
=-\chi(1-\alpha)[\alpha(1-\theta)]^{-1}
\end{gathered}
$$

And:

$$
\begin{aligned}
\frac{\partial M}{\partial \tau^{*}} & =-\lambda \frac{(\omega-\lambda)}{\omega} e^{-\lambda \tau}+\frac{(\omega-\lambda) \lambda}{\omega} e^{(\omega-\lambda) \tau} \\
& =-\lambda \frac{(\omega-\lambda)}{\omega} e^{-\lambda \tau}+\frac{(\omega-\lambda) \lambda}{\omega} e^{\omega \tau} e^{-\lambda \tau} \\
& =\frac{(\omega-\lambda) \lambda}{\omega}\left(e^{\omega \tau}-1\right) e^{-\lambda \tau}
\end{aligned}
$$

Hence:

$$
\begin{aligned}
\frac{d \tau^{*}}{d \theta} & =\frac{-M\left(\tau^{*}\right) \frac{d \chi}{d \theta}}{\chi \frac{d M}{d \tau^{*}}} \\
& =\frac{M\left(\tau^{*}\right) \chi(1-\alpha)[\alpha(1-\theta)]^{-1}}{\chi \frac{(\omega-\lambda) \lambda}{\omega}\left(e^{\omega \tau}-1\right) e^{-\lambda \tau}} \\
& =\frac{\frac{(1-\alpha)}{\alpha}[(1-\theta)]^{-1}}{\chi \frac{\frac{1-\alpha}{\alpha}\left[\Omega(\alpha)-r^{L}\right] \lambda}{\omega}\left(e^{\omega \tau}-1\right) e^{-\lambda \tau}} \\
& =\frac{\omega[(1-\theta)]^{-1}}{\chi\left[\Omega(\alpha)-r^{L}\right] \lambda\left(e^{\omega \tau}-1\right) e^{-\lambda \tau}}>0
\end{aligned}
$$

That can be obtained by replacing $M\left(\tau^{*}\right) \chi=1$ and by using the expression as:

$$
\omega-\lambda=\frac{1-\alpha}{\alpha}\left[\Omega(\alpha)-r^{L}\right]
$$

Finally, applying the implicit function theorem to the expression for $\mathrm{M}\left(\tau^{*}\right)$, one obtains:

$$
\frac{\partial \tau^{*}}{\partial r^{L}}=-\frac{\frac{\partial M}{\partial \omega} \frac{\partial \omega}{\partial r^{L}}}{\frac{\partial M}{\partial \tau^{*}}}
$$




$$
\begin{aligned}
\frac{\partial M}{\partial \omega} & =\left[1-(1-\tau \omega) e^{\tau \omega}\right] \frac{\lambda e^{-\lambda \tau}}{\omega^{2}} \\
\frac{\partial \omega}{\partial r^{L}} & =-\frac{(1-\alpha)}{\alpha} \\
\frac{\partial M}{\partial \tau^{*}} & =\frac{(\omega-\lambda) \lambda}{\omega}\left(e^{\omega \tau}-1\right) e^{-\lambda \tau} \\
\frac{\partial \tau^{*}}{\partial r^{L}}= & \frac{\left[1-(1-\tau \omega) e^{\tau \omega}\right] \frac{\lambda e^{-\lambda \tau}}{\omega^{2}} \frac{(1-\alpha)}{\alpha}}{\frac{1-\alpha}{\alpha}\left[\Omega(\alpha)-r^{L}\right] \frac{\lambda}{\omega}\left(e^{\omega \tau}-1\right) e^{-\lambda \tau}} \\
= & \frac{1-(1-\tau \omega) e^{\tau \omega}}{\omega\left[\Omega(\alpha)-r^{L}\right]\left(e^{\omega \tau}-1\right)}>0 \text { for } \omega \tau>0
\end{aligned}
$$

Proposition 4 If $\alpha>1$, and non-short-selling is assumed, i. e., $\phi_{d}>0$ and $\phi_{f}>0$, the optimal level of inattention is negatively correlated with mean returns on domestic and foreign stocks, positively correlated to the volatility of those assets' returns, and positively correlated to the covariance of such returns:

$$
\begin{aligned}
& \frac{\partial \tau^{*}}{\partial \mu_{d}}<0, \frac{\partial \tau^{*}}{\partial \mu_{f}}<0 \\
& \frac{\partial \tau^{*}}{\partial \sigma_{d}^{2}}>0, \frac{\partial \tau^{*}}{\partial \sigma_{f}^{2}}>0 \\
& \frac{\partial \tau^{*}}{\partial \sigma_{d f}}>0
\end{aligned}
$$

Proof. First, looking at the returns:

$$
\begin{aligned}
\frac{(\omega-\lambda)}{\omega} e^{-\lambda \tau^{*}}+\frac{\lambda}{\omega} e^{(\omega-\lambda) \tau^{*}}-\frac{1}{\chi} & =0 \\
& \text { or } \\
M\left(\tau^{*}\right) \chi & =1
\end{aligned}
$$

Using the implicit function theorem:

$$
\begin{aligned}
\frac{\partial \tau^{*}}{\partial \mu_{f}} & =-\frac{\frac{\partial M}{\partial \mu_{f}}}{\frac{\partial M}{\partial \tau^{*}}}=-\frac{\left(\frac{\partial M}{\partial \lambda} \frac{\partial \lambda}{\partial \Omega(\alpha)} \frac{\partial \Omega(\alpha)}{\partial \mu_{f}}\right)}{\frac{\partial M}{\partial \tau^{*}}} \\
\frac{\partial \tau^{*}}{\partial \mu_{d}} & =-\frac{\frac{\partial M}{\partial \mu_{d}}}{\frac{\partial M}{\partial \tau^{*}}}=-\frac{\left(\frac{\partial M}{\partial \lambda} \frac{\partial \lambda}{\partial \Omega(\alpha)} \frac{\partial \Omega(\alpha)}{\partial \mu_{d}}\right)}{\frac{\partial M}{\partial \tau^{*}}}
\end{aligned}
$$

The common three terms in the previous two derivatives are such that:

$$
\frac{\partial M}{\partial \lambda}=\frac{1}{\lambda} M\left(\tau^{*}\right) e^{-\lambda \tau^{*}}\left[-M\left(\tau^{*}\right)^{-1}+\left(1-\lambda \tau^{*}\right) e^{\lambda \tau^{*}}\right]
$$

Since $M\left(\tau^{*}\right) \chi=1,\left(1-\lambda \tau^{*}\right) e^{\lambda \tau^{*}}<1$, for $\lambda \tau>0$, and $M\left(\tau^{*}\right)>0$, it is true that $\frac{\partial M}{\partial \lambda}<\frac{1}{\lambda} M\left(\tau^{*}\right) e^{-\lambda \tau^{*}}[-\chi+1]$. 
If $\alpha>1, \chi>1$, and hence, $\frac{\partial M}{\partial \lambda}<0$.

In addition, it's easy to obtain that:

$$
\begin{aligned}
\frac{\partial \lambda}{\partial \Omega(\alpha)} & =-\frac{(1-\alpha)}{\alpha}>0, \text { for } \alpha>1 \\
\frac{\partial \Omega(\alpha)}{\partial \mu_{f}} & =\frac{1}{\alpha} \frac{\left(\mu_{d}-r\right) \sigma_{d f}+\left(\mu_{f}-r\right) \sigma_{d}^{2}}{\sigma_{d}^{2} \sigma_{f}^{2}-\sigma_{d f}^{2}} \\
\frac{\partial M}{\partial \tau^{*}} & =\frac{(\omega-\lambda) \lambda}{\omega}\left(e^{\omega \tau}-1\right) e^{-\lambda \tau} \\
& =\frac{1-\alpha}{\alpha}\left[\Omega(\alpha)-r^{L}\right] \frac{\lambda}{\omega}\left(e^{\omega \tau}-1\right) e^{-\lambda \tau}<0, \text { for } \alpha>1
\end{aligned}
$$

However, the term for $\frac{\partial \Omega(\alpha)}{\partial \mu_{f}}$ and $\frac{\partial \Omega(\alpha)}{\partial \mu_{d}}$ can be positive or negative. Recall that:

$$
\begin{aligned}
\Omega(\alpha) \equiv & \left(r+\frac{1}{2} \frac{1}{\alpha}(\mu-R)^{\prime} \Omega^{-1}(\mu-R)\right) \\
= & \left(r+\frac{1}{2} \frac{1}{\alpha}\left(\frac{\left(\mu_{d}-r\right)^{2} \sigma_{f}^{2}-2\left(\mu_{d}-r\right)\left(\mu_{f}-r\right) \sigma_{d f}+\left(\mu_{f}-r\right)^{2} \sigma_{d}^{2}}{\sigma_{d}^{2} \sigma_{f}^{2}-\sigma_{d f}^{2}}\right)\right) \\
\frac{d \Omega(\alpha)}{d \mu} & =\frac{1}{\alpha}(\mu-R)^{\prime} \Omega^{-1}=\phi^{*^{\prime}} \\
& =\frac{1}{\alpha} \frac{1}{\sigma_{d}^{2} \sigma_{f}^{2}-\sigma_{d f}^{2}}\left(\begin{array}{c}
\left(\mu_{d}-r\right) \sigma_{f}^{2}-\left(\mu_{f}-r\right) \sigma_{d f} \\
-\left(\mu_{d}-r\right) \sigma_{d f}+\left(\mu_{f}-r\right) \sigma_{d}^{2}
\end{array}\right)
\end{aligned}
$$

Hence:

$$
\frac{d \Omega(\alpha)}{d \mu_{f}}=\frac{1}{\alpha} \frac{-\left(\mu_{d}-r\right) \sigma_{d f}+\left(\mu_{f}-r\right) \sigma_{d}^{2}}{\sigma_{d}^{2} \sigma_{f}^{2}-\sigma_{d f}^{2}} \lessgtr 0
$$

The analogous derivation follows for the domestic stock market:

$$
\frac{d \Omega(\alpha)}{d \mu_{d}}=\frac{1}{\alpha} \frac{\left(\mu_{d}-r\right) \sigma_{f}^{2}-\left(\mu_{f}-r\right) \sigma_{d f}}{\sigma_{d}^{2} \sigma_{f}^{2}-\sigma_{d f}^{2}} \lessgtr 0
$$

Although the answers to the last derivative is straightforward for the one-asset only case, the analogous is not true for the case with foreign and domestic stocks. In principle, nothing prevents the investor from short selling, and if this is so, $\frac{d \Omega(\alpha)}{d \mu_{f}}$ or $\frac{d \Omega(\alpha)}{d \mu_{d}}$ can attain a negative sign.

Assuming there is no short selling:

$$
\begin{array}{r}
\left(\mu_{d}-r\right) \sigma_{f}^{2}-\left(\mu_{f}-r\right) \sigma_{d f}>0 \\
-\left(\mu_{d}-r\right) \sigma_{d f}+\left(\mu_{f}-r\right) \sigma_{d}^{2}>0
\end{array}
$$


and therefore, $\frac{\partial \Omega(\alpha)}{\partial \mu_{f}}>0$ and $\frac{\partial \Omega(\alpha)}{\partial \mu_{d}}>0$, implying:

$$
\begin{aligned}
& \frac{\partial \tau^{*}}{\partial \mu_{f}}=-\frac{\frac{\partial M}{\partial \mu_{f}}}{\frac{\partial M}{\partial \tau^{*}}}=-\frac{(\overbrace{\frac{\partial M}{\partial \lambda} \frac{\partial \lambda}{\partial \Omega(\alpha)} \frac{\partial \Omega(\alpha)}{\partial \mu_{f}}}^{<0} \overbrace{\underbrace{>0}_{<0}}^{>0}}{\underbrace{\partial 0}_{\frac{\partial M}{\partial \tau^{*}}}}<0 \\
& \frac{\partial \tau^{*}}{\partial \mu_{d}}=-\frac{\frac{\partial M}{\partial \mu_{f}}}{\frac{\partial M}{\partial \tau^{*}}}=-\frac{(\overbrace{\frac{\partial M}{\partial \lambda} \frac{\partial \lambda}{\partial \Omega(\alpha)} \frac{\partial \Omega(\alpha)}{\partial \mu_{d}}}^{<0} \overbrace{\underbrace{>0}_{<0}}^{>0}}{\underbrace{\partial 0}_{\frac{\partial M}{\partial \tau^{*}}}}<0
\end{aligned}
$$

Now, for the variances:

$$
\begin{aligned}
& \frac{\partial \tau^{*}}{\partial \sigma_{f}^{2}}=-\frac{\frac{\partial M}{\partial \sigma_{f}^{2}}}{\frac{\partial M}{\partial \tau^{*}}}=-\frac{\left(\frac{\partial M}{\partial \lambda} \frac{\partial \lambda}{\partial \Omega(\alpha)} \frac{\partial \Omega(\alpha)}{\partial \sigma_{f}^{2}}\right)}{\frac{\partial M}{\partial \tau^{*}}}>0 \\
& \frac{\partial \tau^{*}}{\partial \sigma_{d}^{2}}=-\frac{\frac{\partial M}{\partial \mu_{f}}}{\frac{\partial M}{\partial \tau^{*}}}=-\frac{\left(\frac{\partial M}{\partial \lambda} \frac{\partial \lambda}{\partial \Omega(\alpha)} \frac{\partial \Omega(\alpha)}{\partial \sigma_{d}^{2}}\right)}{\frac{\partial M}{\partial \tau^{*}}}>0
\end{aligned}
$$

Again, the term for $\Omega(\alpha)$ is such that:

$$
\Omega(\alpha) \equiv\left(r+\frac{1}{2} \frac{1}{\alpha}\left(\frac{\left(\mu_{d}-r\right)^{2} \sigma_{f}^{2}-2\left(\mu_{d}-r\right)\left(\mu_{f}-r\right) \sigma_{d f}+\left(\mu_{f}-r\right)^{2} \sigma_{d}^{2}}{\sigma_{d}^{2} \sigma_{f}^{2}-\sigma_{d f}^{2}}\right)\right)
$$

$$
\begin{aligned}
& \frac{d \Omega(\alpha)}{d \sigma_{f}^{2}}=\frac{1}{2} \frac{1}{\alpha}\left(\frac{2\left(\mu_{d}-r\right)^{2} \sigma_{f}\left(\sigma_{d}^{2} \sigma_{f}^{2}-\sigma_{d f}^{2}\right)-\left(\begin{array}{c}
\left(\mu_{d}-r\right)^{2} \sigma_{f}^{2} \\
-2\left(\mu_{d}-r\right)\left(\mu_{f}-r\right) \sigma_{d f} \\
+\left(\mu_{f}-r\right)^{2} \sigma_{d}^{2}
\end{array}\right) 2 \sigma_{d}^{2} \sigma_{f}}{\left(\sigma_{d}^{2} \sigma_{f}^{2}-\sigma_{d f}^{2}\right)^{2}}\right) \\
& =\frac{1}{2} \frac{1}{\alpha}\left(\frac{2\left(\mu_{d}-r\right)^{2} \sigma_{f}\left(\sigma_{d}^{2} \sigma_{f}^{2}-\sigma_{d f}^{2}\right)-\left(\begin{array}{c}
\left(\mu_{d}-r\right)^{2} \sigma_{f}^{2}-2\left(\mu_{d}-r\right)\left(\mu_{f}-r\right) \sigma_{d f} \\
+\left(\mu_{f}-r\right)^{2} \sigma_{d}^{2}
\end{array}\right) 2 \sigma_{d}^{2} \sigma_{f}}{\left(\sigma_{d}^{2} \sigma_{f}^{2}-\sigma_{d f}^{2}\right)^{2}}\right)
\end{aligned}
$$


One, hence, has to test the sign of the numerator of the above expression. Rearranging the terms:

$$
\begin{aligned}
& \left(\mu_{d}-r\right)^{2} \sigma_{f}\left(\sigma_{d}^{2} \sigma_{f}^{2}-\sigma_{d f}^{2}\right)-\left(\begin{array}{c}
\sigma_{d}^{2} \sigma_{f}\left(\mu_{d}-r\right)^{2} \sigma_{f}^{2}-2 \sigma_{d}^{2} \sigma_{f}\left(\mu_{d}-r\right)\left(\mu_{f}-r\right) \sigma_{d f} \\
+\sigma_{d}^{2} \sigma_{f}\left(\mu_{f}-r\right)^{2} \sigma_{d}^{2}
\end{array}\right) \\
= & \left(\mu_{d}-r\right) \sigma_{f} \sigma_{d f}\left(\left(\mu_{f}-r\right) \sigma_{d}^{2}-\left(\mu_{d}-r\right) \sigma_{d f}\right) \\
& +\sigma_{d}^{2} \sigma_{f}\left(\mu_{f}-r\right)\left(\left(\mu_{d}-r\right) \sigma_{d f}-\left(\mu_{f}-r\right) \sigma_{d}^{2}\right) \\
= & \sigma_{f}\left(\left(\mu_{f}-r\right) \sigma_{d}^{2}-\left(\mu_{d}-r\right) \sigma_{d f}\right)\left(\left(\mu_{d}-r\right) \sigma_{d f}-\left(\mu_{f}-r\right) \sigma_{d}^{2}\right) \\
= & -\sigma_{f}\left(\left(\mu_{f}-r\right) \sigma_{d}^{2}-\left(\mu_{d}-r\right) \sigma_{d f}\right)^{2} \\
< & 0
\end{aligned}
$$

The analogous follows for the domestic stock:

$$
\begin{aligned}
& \frac{d \Omega(\alpha)}{d \sigma_{d}^{2}}=\frac{1}{2} \frac{1}{\alpha}\left(\frac{2\left(\mu_{f}-r\right)^{2} \sigma_{d}\left(\sigma_{d}^{2} \sigma_{f}^{2}-\sigma_{d f}^{2}\right)-\left(\begin{array}{c}
\left(\mu_{d}-r\right)^{2} \sigma_{f}^{2} \\
-2\left(\mu_{d}-r\right)\left(\mu_{f}-r\right) \sigma_{d f} \\
+\left(\mu_{f}-r\right)^{2} \sigma_{d}^{2}
\end{array}\right) 2 \sigma_{f}^{2} \sigma_{d}}{\left(\sigma_{d}^{2} \sigma_{f}^{2}-\sigma_{d f}^{2}\right)^{2}}\right) \\
& =\frac{1}{2} \frac{1}{\alpha}\left(\frac{2\left(\mu_{f}-r\right)^{2} \sigma_{d}\left(\sigma_{d}^{2} \sigma_{f}^{2}-\sigma_{d f}^{2}\right)-\left(\begin{array}{c}
\left(\mu_{d}-r\right)^{2} \sigma_{f}^{2}-2\left(\mu_{d}-r\right)\left(\mu_{f}-r\right) \sigma_{d f} \\
+\left(\mu_{f}-r\right)^{2} \sigma_{d}^{2}
\end{array}\right) 2 \sigma_{f}^{2} \sigma_{d}}{\left(\sigma_{d}^{2} \sigma_{f}^{2}-\sigma_{d f}^{2}\right)^{2}}\right)
\end{aligned}
$$

The numerator is such that:

$$
\begin{aligned}
& \left(\mu_{f}-r\right)^{2} \sigma_{d}\left(\sigma_{d}^{2} \sigma_{f}^{2}-\sigma_{d f}^{2}\right)-\left(\left(\mu_{d}-r\right)^{2} \sigma_{f}^{2}-2\left(\mu_{d}-r\right)\left(\mu_{f}-r\right) \sigma_{d f}+\left(\mu_{f}-r\right)^{2} \sigma_{d}^{2}\right) \sigma_{f}^{2} \sigma_{d} \\
= & \left(\mu_{f}-r\right)^{2} \sigma_{d} \sigma_{d}^{2} \sigma_{f}^{2}-\left(\mu_{f}-r\right)^{2} \sigma_{d} \sigma_{d f}^{2}-\sigma_{f}^{2} \sigma_{d}\left(\mu_{d}-r\right)^{2} \sigma_{f}^{2} \\
& +2 \sigma_{f}^{2} \sigma_{d}\left(\mu_{d}-r\right)\left(\mu_{f}-r\right) \sigma_{d f}-\sigma_{f}^{2} \sigma_{d}\left(\mu_{f}-r\right)^{2} \sigma_{d}^{2} \\
= & \left(\mu_{d}-r\right)\left(\mu_{f}-r\right) \sigma_{f}^{2} \sigma_{d} \sigma_{d f}-\left(\mu_{f}-r\right)^{2} \sigma_{d} \sigma_{d f}^{2} \\
& +\left(\mu_{d}-r\right)\left(\mu_{f}-r\right) \sigma_{f}^{2} \sigma_{d} \sigma_{d f}-\left(\mu_{d}-r\right)^{2} \sigma_{f}^{4} \sigma_{d} \\
= & \sigma_{d}\left(\left(\mu_{d}-r\right) \sigma_{f}^{2}-\left(\mu_{f}-r\right) \sigma_{d f}\right)\left(\left(\mu_{f}-r\right) \sigma_{d f}-\left(\mu_{d}-r\right) \sigma_{f}^{2}\right) \\
= & -\sigma_{d}\left(\left(\mu_{d}-r\right) \sigma_{f}^{2}-\left(\mu_{f}-r\right) \sigma_{d f}\right)^{2} \\
< & 0
\end{aligned}
$$

Therefore: 


$$
\begin{aligned}
& \frac{\partial \tau^{*}}{\partial \sigma_{f}^{2}}=-\frac{\frac{\partial M}{\partial \sigma_{f}^{2}}}{\frac{\partial M}{\partial \tau^{*}}}=-\frac{(\overbrace{\frac{\partial M}{\partial \lambda} \frac{\partial \lambda}{\partial \Omega(\alpha)} \frac{\partial \Omega(\alpha)}{\partial \sigma_{f}^{2}}}^{<0} \overbrace{\underbrace{<0}_{<0}}^{<0})}{\underbrace{\frac{\partial M}{\partial \tau^{*}}}_{>0}}>0 \\
& \frac{\partial \tau^{*}}{\partial \sigma_{d}^{2}}=-\frac{\frac{\partial M}{\partial \mu_{f}}}{\frac{\partial M}{\partial \tau^{*}}}=-\frac{(\overbrace{\frac{\partial M}{\partial \lambda} \frac{\partial \lambda}{\partial \Omega(\alpha)} \frac{\partial \Omega(\alpha)}{\partial \sigma_{d}^{2}}}^{>0} \overbrace{\underbrace{<0}_{<0}}^{<0})}{\underbrace{\partial 0}_{\frac{\partial M}{\partial \tau^{*}}}}>0
\end{aligned}
$$

Observe that for the variance case, there is no need for the restriction on non-short-selling. Finally, for the covariance, the optimal level of inattention is increasing in the covariance of the asset returns. Applying the Implicit Function Theorem:

$$
\frac{\partial \tau^{*}}{\partial \sigma_{d f}}=-\frac{\frac{\partial M}{\partial \sigma_{d f}}}{\frac{\partial M}{\partial \tau^{*}}}=-\frac{\left(\frac{\partial M}{\partial \lambda} \frac{\partial \lambda}{\partial \Omega(\alpha)} \frac{\partial \Omega(\alpha)}{\partial \sigma_{d f}}\right)}{\frac{\partial M}{\partial \tau^{*}}}
$$

As previously obtained:

$$
\begin{aligned}
& \frac{\partial M}{\partial \lambda}=\frac{1}{\lambda} M\left(\tau^{*}\right) e^{-\lambda \tau^{*}}\left[-M\left(\tau^{*}\right)^{-1}+\left(1-\lambda \tau^{*}\right) e^{\lambda \tau^{*}}\right]<0, \text { for } \alpha>1 \\
& \frac{\partial \lambda}{\partial \Omega(\alpha)}=-\frac{(1-\alpha)}{\alpha} \\
& \frac{\partial M}{\partial \tau^{*}}=\frac{1-\alpha}{\alpha}\left[\Omega(\alpha)-r^{L}\right] \frac{\lambda}{\omega}\left(e^{\omega \tau}-1\right) e^{-\lambda \tau} \\
& \frac{\partial \Omega(\alpha)}{\partial \sigma_{d f}}=\frac{1}{2} \frac{1}{\alpha}\left(\frac{\left[\begin{array}{c}
-2\left(\mu_{d}-r\right)\left(\mu_{f}-r\right)\left(\sigma_{d}^{2} \sigma_{f}^{2}-\sigma_{d f}^{2}\right)- \\
\left(-2 \sigma_{d, f}\right)\left(\left(\mu_{d}-r\right)^{2} \sigma_{f}^{2}-2\left(\mu_{d}-r\right)\left(\mu_{f}-r\right) \sigma_{d f}+\left(\mu_{f}-r\right)^{2} \sigma_{d}^{2}\right)
\end{array}\right]}{\left(\sigma_{d}^{2} \sigma_{f}^{2}-\sigma_{d f}^{2}\right)^{2}}\right) \\
& =\frac{1}{2} \frac{1}{\alpha}\left(\frac{\left[\begin{array}{c}
-2\left(\mu_{d}-r\right)\left(\mu_{f}-r\right) \sigma_{d}^{2} \sigma_{f}^{2}+2\left(\mu_{d}-r\right)\left(\mu_{f}-r\right) \sigma_{d f}^{2} \\
+2 \sigma_{d f}\left(\mu_{d}-r\right)^{2} \sigma_{f}^{2}-4\left(\mu_{d}-r\right)\left(\mu_{f}-r\right) \sigma_{d f}+2 \sigma_{d f}\left(\mu_{f}-r\right)^{2} \sigma_{d}^{2}
\end{array}\right]}{\left(\sigma_{d}^{2} \sigma_{f}^{2}-\sigma_{d f}^{2}\right)^{2}}\right)
\end{aligned}
$$


Since the denominator is positive, it lacks to test the numerator:

$$
\begin{aligned}
= & -\left(\mu_{d}-r\right)\left(\mu_{f}-r\right) \sigma_{d}^{2} \sigma_{f}^{2}+\left(\mu_{d}-r\right)\left(\mu_{f}-r\right) \sigma_{d f}^{2}+\sigma_{d f}\left(\mu_{d}-r\right)^{2} \sigma_{f}^{2} \\
& -2\left(\mu_{d}-r\right)\left(\mu_{f}-r\right) \sigma_{d f}+\sigma_{d f}\left(\mu_{f}-r\right)^{2} \sigma_{d}^{2} \\
< & -\left(\mu_{d}-r\right)\left(\mu_{f}-r\right) \sigma_{d}^{2} \sigma_{f}^{2}+\left(\mu_{d}-r\right)\left(\mu_{f}-r\right) \sigma_{d f}-2\left(\mu_{d}-r\right)\left(\mu_{f}-r\right) \sigma_{d f} \\
& +\sigma_{d f}\left(\mu_{d}-r\right)^{2} \sigma_{f}^{2}+\sigma_{d f}\left(\mu_{f}-r\right)^{2} \sigma_{d}^{2} \\
= & -\left(\mu_{d}-r\right)\left(\mu_{f}-r\right) \sigma_{d}^{2} \sigma_{f}^{2}-\left(\mu_{d}-r\right)\left(\mu_{f}-r\right) \sigma_{d f} \\
& +\sigma_{d f}\left(\mu_{d}-r\right)^{2} \sigma_{f}^{2}+\sigma_{d f}\left(\mu_{f}-r\right)^{2} \sigma_{d}^{2} \\
= & \left(\mu_{d}-r\right) \sigma_{f}^{2}\left(\left(\mu_{d}-r\right) \sigma_{d f}-\left(\mu_{f}-r\right) \sigma_{d}^{2}\right)+\sigma_{d f}\left(\mu_{f}-r\right)\left(\left(\mu_{f}-r\right) \sigma_{d}^{2}-\left(\mu_{d}-r\right) \sigma_{d f}\right) \\
= & \underbrace{\left(\left(\mu_{d}-r\right) \sigma_{d f}-\left(\mu_{f}-r\right) \sigma_{d}^{2}\right)}_{<0} \underbrace{\left(\left(\mu_{d}-r\right) \sigma_{f}^{2}-\sigma_{d f}\left(\mu_{f}-r\right)\right)}_{>0}<0
\end{aligned}
$$

and hence, $\frac{d \Omega(\alpha)}{d \sigma_{d f}}<0$. Therefore, one gets:

$$
\begin{aligned}
\frac{\partial \tau^{*}}{\partial \sigma_{d f}} & =-\frac{(\overbrace{\frac{\partial M}{\partial \lambda}}^{<0}\left(-\frac{(1-\alpha)}{\alpha}\right) \overbrace{\frac{\partial \Omega(\alpha)}{\partial \sigma_{d f}}}^{<0})}{\frac{\frac{\partial M}{\partial \sigma_{d f}}}{\partial \tau^{*}}}=-\frac{(\overbrace{\frac{\partial M}{\partial \lambda} \frac{\partial \Omega(\alpha)}{\partial \sigma_{d f}}}^{<0})}{\left.\partial \Omega(\alpha)-r^{L}\right] \frac{\lambda}{\omega}\left(e^{\omega \tau}-1\right) e^{-\lambda \tau}} \\
= & \underbrace{\left[\Omega(\alpha)-r^{L}\right] \frac{\lambda}{\omega}\left(e^{\omega \tau}-1\right) e^{-\lambda \tau}}_{>0}>0
\end{aligned}
$$

Observe that had I not imposed the non-short-selling condition, the sign of

$$
-\left(\left(\mu_{f}-r\right) \sigma_{d}^{2}-\left(\mu_{d}-r\right) \sigma_{d f}\right)\left(\left(\mu_{d}-r\right) \sigma_{f}^{2}-\sigma_{d f}\left(\mu_{f}-r\right)\right)
$$

would be undetermined, since the two terms in the parameters have to either have opposite signs or be both positive (for the non-short-selling condition case).

Proposition 5 If $\alpha>1$, the (approximately) optimal level of inattention is smaller once foreign stock holdings is introduced into the model., i.e.:

$$
\hat{\tau}^{*}<\tau_{d}^{*}
$$


Proof. We are trying to check if:

$$
\begin{aligned}
\left(\frac{2\left(\chi^{-1}-1\right)}{(\omega-\lambda) \lambda}\right)^{\frac{1}{2}} & <\left(\frac{2\left(\chi^{-1}-1\right)}{\left(\omega-\lambda_{d}\right) \lambda_{d}}\right)^{\frac{1}{2}} \\
\frac{\left(\chi^{-1}-1\right)}{(\omega-\lambda) \lambda} & <\frac{\left(\chi^{-1}-1\right)}{\left(\omega-\lambda_{d}\right) \lambda_{d}}
\end{aligned}
$$

i.e., if

$$
\left(\omega-\lambda_{d}\right) \lambda_{d}>(\omega-\lambda) \lambda
$$

Recall that because $0<\theta<1$, and I assume $\omega<\lambda$ and $\omega<\lambda_{d}$, the above expression is the correct one to be verified.

Recall that:

$$
\begin{aligned}
\lambda & =\frac{\rho-(1-\alpha)\left(r+\frac{1}{2} \frac{1}{\alpha}(\mu-R)^{\prime} \Omega^{-1}(\mu-R)\right)}{\alpha} \\
\lambda_{d} & =\frac{\rho-(1-\alpha)\left(r+\frac{1}{2} \frac{1}{\alpha} \frac{\left(\mu_{d}-r\right)^{2}}{\sigma_{d}^{2}}\right)}{\alpha}
\end{aligned}
$$

One wants to check if $\left(\omega-\lambda_{d}\right) \lambda_{d}>(\omega-\lambda) \lambda$. Rewriting this expression:

$$
\begin{aligned}
& =\left(\omega-\lambda_{d}\right) \lambda_{d}-(\omega-\lambda) \lambda= \\
& =\omega\left(\lambda_{d}-\lambda\right)-\left(\lambda_{d}^{2}-\lambda^{2}\right) \\
& =\omega\left(\lambda_{d}-\lambda\right)-\left(\lambda_{d}-\lambda\right)\left(\lambda_{d}+\lambda\right) \\
& =\left(\lambda_{d}-\lambda\right)\left(\omega-\lambda_{d}-\lambda\right) \\
& =\left[\frac{\rho-(1-\alpha)\left(r+\frac{1}{2} \frac{1}{\alpha} \frac{\left(\mu_{d}-r\right)^{2}}{\sigma_{d}^{2}}\right)}{\alpha}-\frac{\rho-(1-\alpha)\left(r+\frac{1}{2} \frac{1}{\alpha}(\mu-R)^{\prime} \Omega^{-1}(\mu-R)\right)}{\alpha}\right]\left(\omega-\lambda_{d}-\lambda\right) \\
& =\left[\frac{\rho}{\alpha}-\frac{(1-\alpha)}{\alpha}\left(r+\frac{1}{2} \frac{1}{\alpha} \frac{\left(\mu_{d}-r\right)^{2}}{\sigma_{d}^{2}}\right)-\frac{\rho}{\alpha}+\frac{(1-\alpha)}{\alpha}\left(r+\frac{1}{2} \frac{1}{\alpha}(\mu-R)^{\prime} \Omega^{-1}(\mu-R)\right)\right]\left(\omega-\lambda_{d}-\lambda\right) \\
& =\frac{(1-\alpha)}{\alpha}\left[-r-\frac{1}{2} \frac{1}{\alpha} \frac{\left(\mu_{d}-r\right)^{2}}{\sigma_{d}^{2}}+r+\frac{1}{2} \frac{1}{\alpha}(\mu-R)^{\prime} \Omega^{-1}(\mu-R)\right]\left(\omega-\lambda_{d}-\lambda\right) \\
& =\frac{1}{2} \frac{1}{\alpha} \frac{(1-\alpha)}{\alpha}\left[-\frac{\left(\mu_{d}-r\right)^{2}}{\sigma_{d}^{2}}+(\mu-R)^{\prime} \Omega^{-1}(\mu-R)\right]\left(\omega-\lambda_{d}-\lambda\right) \\
& =\frac{1}{2} \frac{1}{\alpha} \frac{(1-\alpha)}{\alpha}\left[\frac{\left(\mu_{f}-r\right)^{2} \sigma_{d}^{4}+\left(\mu_{d}-r\right)^{2} \sigma_{d f}-2\left(\mu_{d}-r\right)\left(\mu_{f}-r\right) \sigma_{d f} \sigma_{d}^{2}}{\left(\sigma_{d}^{2} \sigma_{f}^{2}-\sigma_{d f}^{2}\right) \sigma_{d}^{2}}\right]\left(\frac{\rho-(1-\alpha) r^{L}}{\alpha}-\lambda_{d}-\lambda\right)
\end{aligned}
$$


The denominator of the term in the brackets is positive since it corresponds to the determinant of the variance-covariance matrix. The numerator is such that:

$$
\begin{aligned}
& \left(\mu_{f}-r\right)^{2} \sigma_{d}^{4}+\left(\mu_{d}-r\right)^{2} \sigma_{d f}-2\left(\mu_{d}-r\right)\left(\mu_{f}-r\right) \sigma_{d f} \sigma_{d}^{2} \\
= & \sigma_{d}^{2}\left(\mu_{f}-r\right)\left(\left(\mu_{f}-r\right) \sigma_{d}^{2}-\left(\mu_{d}-r\right) \sigma_{d f}\right)+\sigma_{d f}\left(\mu_{d}-r\right)\left(\left(\mu_{d}-r\right) \sigma_{d f}-\left(\mu_{f}-r\right) \sigma_{d}^{2}\right) \\
= & \left(\left(\mu_{f}-r\right) \sigma_{d}^{2}-\left(\mu_{d}-r\right) \sigma_{d f}\right)\left(\left(\mu_{f}-r\right) \sigma_{d}^{2}-\left(\mu_{d}-r\right) \sigma_{d f}\right) \\
= & \left(\left(\mu_{f}-r\right) \sigma_{d}^{2}-\left(\mu_{d}-r\right) \sigma_{d f}\right)^{2}>0
\end{aligned}
$$

The term in parenthesis equals:

$$
\begin{aligned}
& =\left(\begin{array}{c}
\frac{\rho-(1-\alpha) r^{L}}{\alpha}-\frac{\rho-(1-\alpha)\left(r+\frac{1}{2} \frac{1}{\alpha} \frac{\left(\mu_{d}-r\right)^{2}}{\sigma_{d}^{2}}\right)}{\alpha} \\
-\frac{\rho-(1-\alpha)\left(r+\frac{1}{2} \frac{1}{\alpha}(\mu-R)^{\prime} \Omega^{-1}(\mu-R)\right)}{\alpha}
\end{array}\right) \\
& =-\frac{\rho}{\alpha}+\frac{(1-\alpha)}{\alpha}\left(-r^{L}+2 r+\frac{1}{2} \frac{1}{\alpha}\left(\frac{\left(\mu_{d}-r\right)^{2}}{\sigma_{d}^{2}}+(\mu-R)^{\prime} \Omega^{-1}(\mu-R)\right)\right) \\
& =-\frac{\rho}{\alpha}-\frac{(1-\alpha) r^{L}}{\alpha}+2 \frac{(1-\alpha) r}{\alpha}+\left[\frac{1}{2} \frac{1}{\alpha} \frac{(1-\alpha)}{\alpha}\left(\frac{\left(\mu_{d}-r\right)^{2}}{\sigma_{d}^{2}}+(\mu-R)^{\prime} \Omega^{-1}(\mu-R)\right)\right]
\end{aligned}
$$

For $\alpha>1$, the above term in brackets is negative. For the remainder of the expression:

$$
\begin{aligned}
& -\frac{\rho}{\alpha}-\frac{(1-\alpha) r^{L}}{\alpha}+2 \frac{(1-\alpha) r}{\alpha} \\
= & \frac{\rho}{\alpha}-\frac{(1-\alpha) r^{L}}{\alpha}-2\left(\frac{\rho}{\alpha}-\frac{(1-\alpha) r}{\alpha}\right) \\
< & \frac{\rho}{\alpha}-\frac{(1-\alpha) r^{L}}{\alpha}-2\left(\frac{\rho}{\alpha}-\frac{(1-\alpha) r^{L}}{\alpha}\right) \\
= & -\left(\frac{\rho}{\alpha}-\frac{(1-\alpha) r^{L}}{\alpha}\right)=-\omega \\
< & 0
\end{aligned}
$$

Therefore, $\left(\omega-\lambda_{d}\right) \lambda_{d}-(\omega-\lambda) \lambda$ equals:

$$
\begin{aligned}
& =\left(\lambda_{d}-\lambda\right)\left(\omega-\lambda_{d}-\lambda\right) \\
& =\frac{1}{2} \frac{1}{\alpha} \underbrace{\frac{(1-\alpha)}{\alpha}}_{<0} \underbrace{\left[\frac{(\mu f-r)^{2} \sigma_{d}^{4}+\left(\mu_{d}-r\right)^{2} \sigma_{d f}-2\left(\mu_{d}-r\right)\left(\mu_{f}-r\right) \sigma_{d f} \sigma_{d}^{2}}{\left(\sigma_{d}^{2} \sigma_{f}^{2}-\sigma_{d f}^{2}\right) \sigma_{d}^{2}}\right]}_{>0} \underbrace{\left(\frac{\rho-(1-\alpha) r^{L}}{\alpha}-\lambda_{d}-\lambda\right)}_{<0}
\end{aligned}
$$

Hence:

$$
\begin{aligned}
\left(\omega-\lambda_{d}\right) \lambda_{d} & >(\omega-\lambda) \lambda \\
& \Rightarrow \quad \hat{\tau}^{*}<\tau_{d}^{*}
\end{aligned}
$$

